\title{
Exploring the implications of autonomous vehicles: a comprehensive review
}

\author{
Kareem Othman ${ }^{1,2}$ (1)
}

Received: 19 June 2021 / Accepted: 5 February 2022 / Published online: 1 March 2022

(c) Springer Nature Switzerland AG 2022

\begin{abstract}
Over the last few years, a large emphasis has been devoted to autonomous vehicles (AVs), as vehicle automation promises a large number of benefits such as: improving mobility and minimization of energy and emissions. Additionally, AVs represent a major tool in the fight against pandemics as autonomous vehicles can be used to transport people while maintaining isolation and sterilization. Thus, manufacturers are racing to introduce AVs as fast as possible. However, laws and regulations are not yet ready for this change and the legal sector is following the development of autonomous vehicles instead of taking the lead. This paper provides a comprehensive review of the previous studies in the transportation field that involve AVs with the aim of exploring the implications of AVs on the safety, public behaviour, land use, economy, society and environment, public health, and benefits of autonomous vehicles in fighting pandemics.
\end{abstract}

Keywords Autonomous vehicles · Implications · Public behaviour · Implications on society · Implications on land use · Pandemic

\section{Abbreviations}

AV Autonomous vehicle

SAV Shared autonomous vehicle

VKT Vehicle kilometre travelled

VOT Value of time

\section{Introduction}

Automation of vehicles has always attracted researchers: starting with the vehicle-to-vehicle communication system in the 1920s using radio waves [1], then the development of the vehicle's electromagnetic guidance in the 1930s and 1940s, or adding magnets to vehicles for the testing of smart highways during the 1950s and 1960s [2]. In 1980, Mercedes-Benz partnered with Bundeswehr University in Munich and invented the first autonomous vehicle in the world that opened the way towards thinking about legislation

Kareem Othman

kareem.othman@mail.utoronto.ca;

karemmohamed1993@cu.edu.eg

1 Civil Engineering Department, University of Toronto, $35 \mathrm{St}$ George St, Toronto, ON M5S 1A4, Canada

2 Faculty of Engineering, Public works department, Cairo University, Giza, Egypt adaptation [3]. Since this point in time, many companies have started working on developing autonomous vehicles [4].

Based on the National Highway and Transportation Safety Administration, there are 5 levels of AV functionality: level 0: no automation, level 1: automation of one control function such as lane keep assist or autonomous control, level 2: automation of two control functions, level 3: limited self-driving but expect the driver to take control at any time with adequate warning, level 4: drivers are not expected to take control at any time of the trip, and level 5: full selfdriving with no human control [5, 6].

In the last decade, autonomous vehicles (AVs) have undergone tremendous improvement as both research and industry are putting significant efforts into developing AVs [7]. For example, Google launched the Google self-driving car project in 2009 with the vision of providing fully AVs by 2020 [8]. Uber partnered with Volvo and announced the development of the third version of its self-driving vehicle and they will start testing it by 2020 [9]. In 2014, Apple launched the AV project "Project Titan" with the vision of providing AVs by 2016; however, many issues such as leadership issue had an impact on the project and now it is expected that Apple car will be in the market between 2023 and 2025 [10]. Additionally, many start-up companies launched with the aim of developing AVs. In 2014, Zoox 
was founded to provide electric and autonomous vehicles and its value reached $3.2 \$$ billion by 2018 [11]. Moreover, cities allowed testing and deployment of AVs on public roads. For example, in 2018, 29 of the US states allowed testing AVs on their roads. [12,13]. Such pilot studies are mainly intended to test self-driving technology and public attitude and behaviour. However, till the moment there is no large-scale implementation of AV fleet in a given country. Additionally, there are many obstacles that might hinder the introduction of the AVs such as laws and regulations, public acceptance, ethical issues, and the development of the technology itself.

This paper reviews previous studies in the area of autonomous vehicles with the aim of revealing the implications of autonomous vehicles on safety, public behaviour, land use, economy, society, environment, public health.

\section{Methodology and work cited}

This state of the art reviews the existing literature on the topic of implications of automated vehicles. The databases and search engines used were Scopus, Web of Science, ScienceDirect, SPRINGER LINK, IEEE Xplore, and TRID. The keywords used were: implications of automated vehicles; autonomous vehicles; self-driving cars; road capacity and automated vehicles; autonomous vehicles and society; autonomous vehicles and economy; autonomous vehicles simulation; agent-based autonomous vehicles; autonomous mobility; and shared autonomous vehicles. Only reports in English were included from 2010 onwards. The obtained studies were screened based on their relevance and topics. Additional papers were obtained from the references of the screened papers. Scopus results indicated the sources, "Transportation Research Part C: Emerging Technologies", "Transportation Research Record", "Transportation
Research Part A: Policy and Practice", and "Transportation Research Procedia", as the most frequent resource used in this study.

\section{Research contribution}

Research in AVs has gained significant attention from researchers around the world and research in the implications of $\mathrm{AVs}$ is not an exception. There are a large number of studies in the literature that discuss the implications of AVs. Table 1 summarizes some of these studies. Most of these studies focus on the implications of AVs on one branch only, such as the implications of $\mathrm{AVs}$ on the environment, and ignore the other implications, which might be misleading. Thus, in this paper, a holistic review or a comprehensive review is conducted, and a holistic analysis is conducted in order to discuss the overall implications of AVs and reveal the intertwined relations between the studied factors. This holistic review provides the chance to explore the implications of AVs in new novel areas such as:

- Implications of AVs on the public transit.

- Implications of COVID-19 on the public attitude towards AVs.

- AVs in developing countries and the challenges that faces AVs in developing countries.

- Finally, this study provides a figure that holistically summarizes the strengths, weaknesses, opportunities, threats of AV technology (Figure-5).

Tables 2 and 3 summarize the results of previous studies that focus on the implications of AVs.
Table 1 Selected AV review papers and their scope

\begin{tabular}{ll}
\hline Study & Scope \\
\hline Narayanan et al. (2020) [105] & Implications of shared AVs on multiple branches \\
Kopelias et al. (2019) [106] & Environmental impact of AVs \\
Spence et al. (2020) [107] & Implications of AVs on the public behaviour \\
Sohrabi et al. (2020) [108] & Implication of AVs on the public health \\
Hao and Yamamoto (2018) [109] & Implications of shared AVs on the public behaviour \\
Gandia et al. (2019) [110] & $\begin{array}{l}\text { Scientometric and bibliometric review of AVs } \\
\text { Peng et al. (2020) [111] }\end{array}$ \\
Faisal et al. (2019) [112] & $\begin{array}{l}\text { Scientometric and bibliometric review of AVs } \\
\text { Rojas-Rueda et al. (2020) [113] }\end{array}$ \\
Sun et a. (2017) [114] & Implications of AVs on the landscape \\
& $\begin{array}{c}\text { Implications of AVs on the travel behaviour and the } \\
\text { current business models }\end{array}$ \\
\hline
\end{tabular}




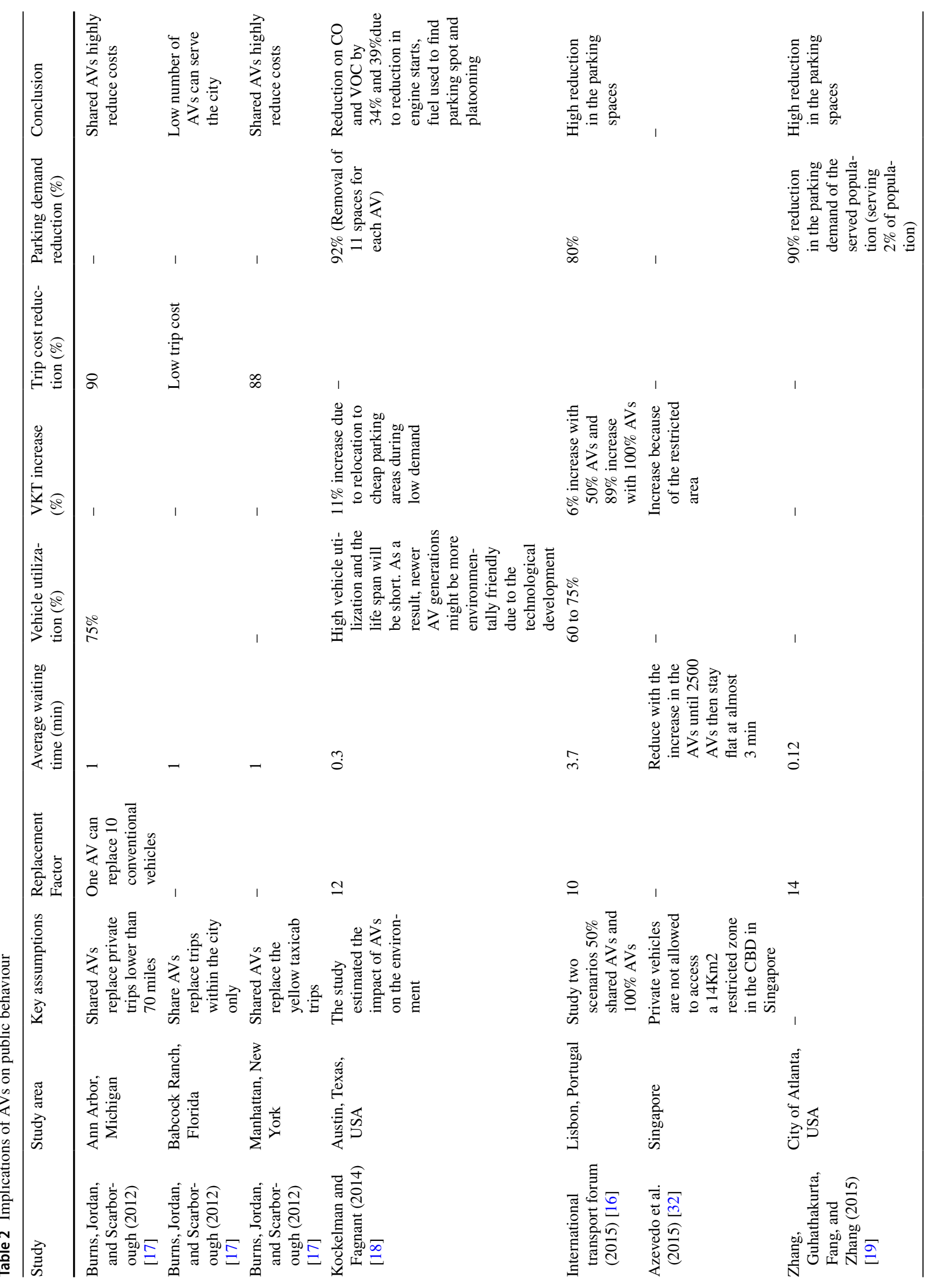




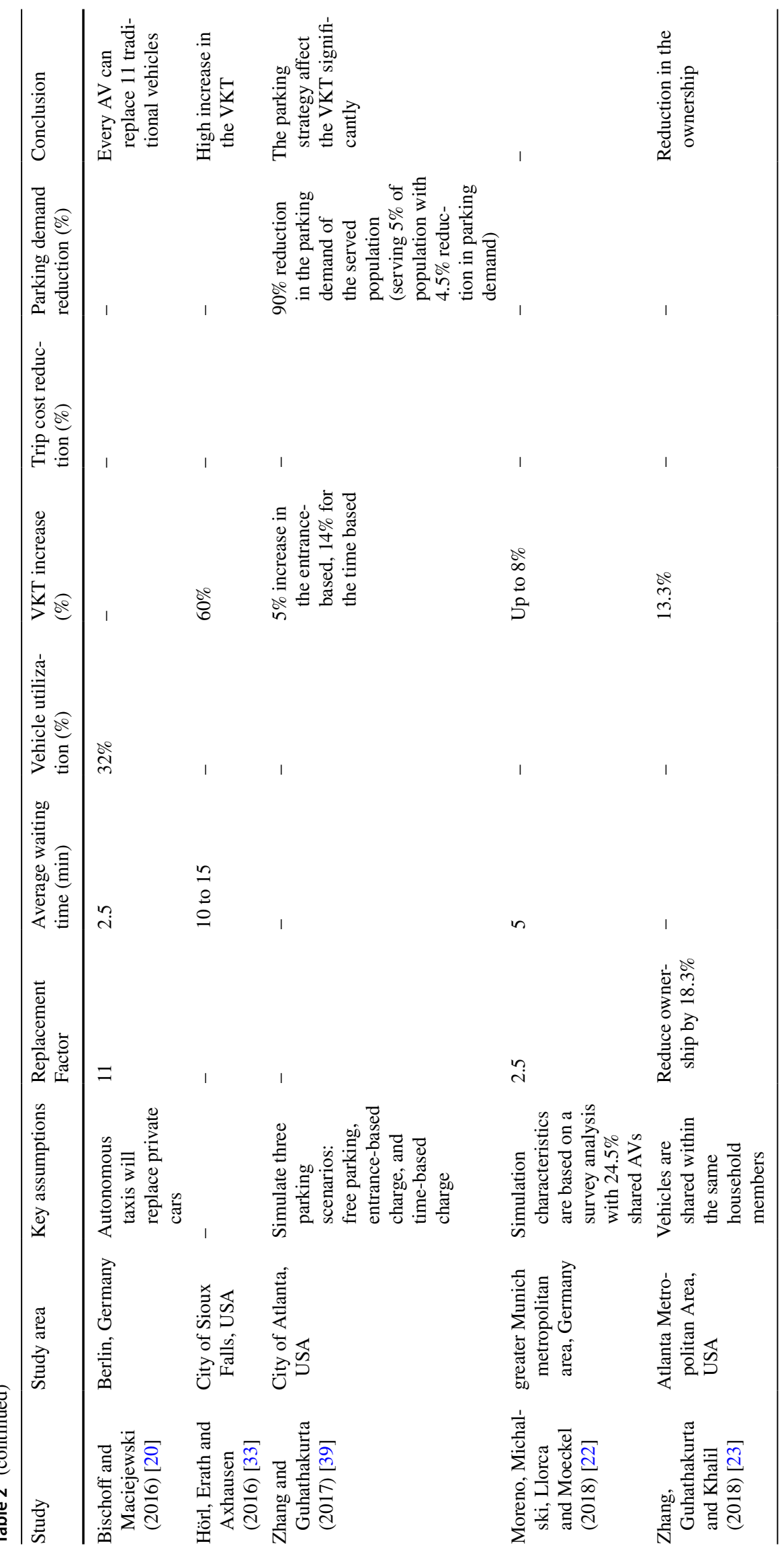




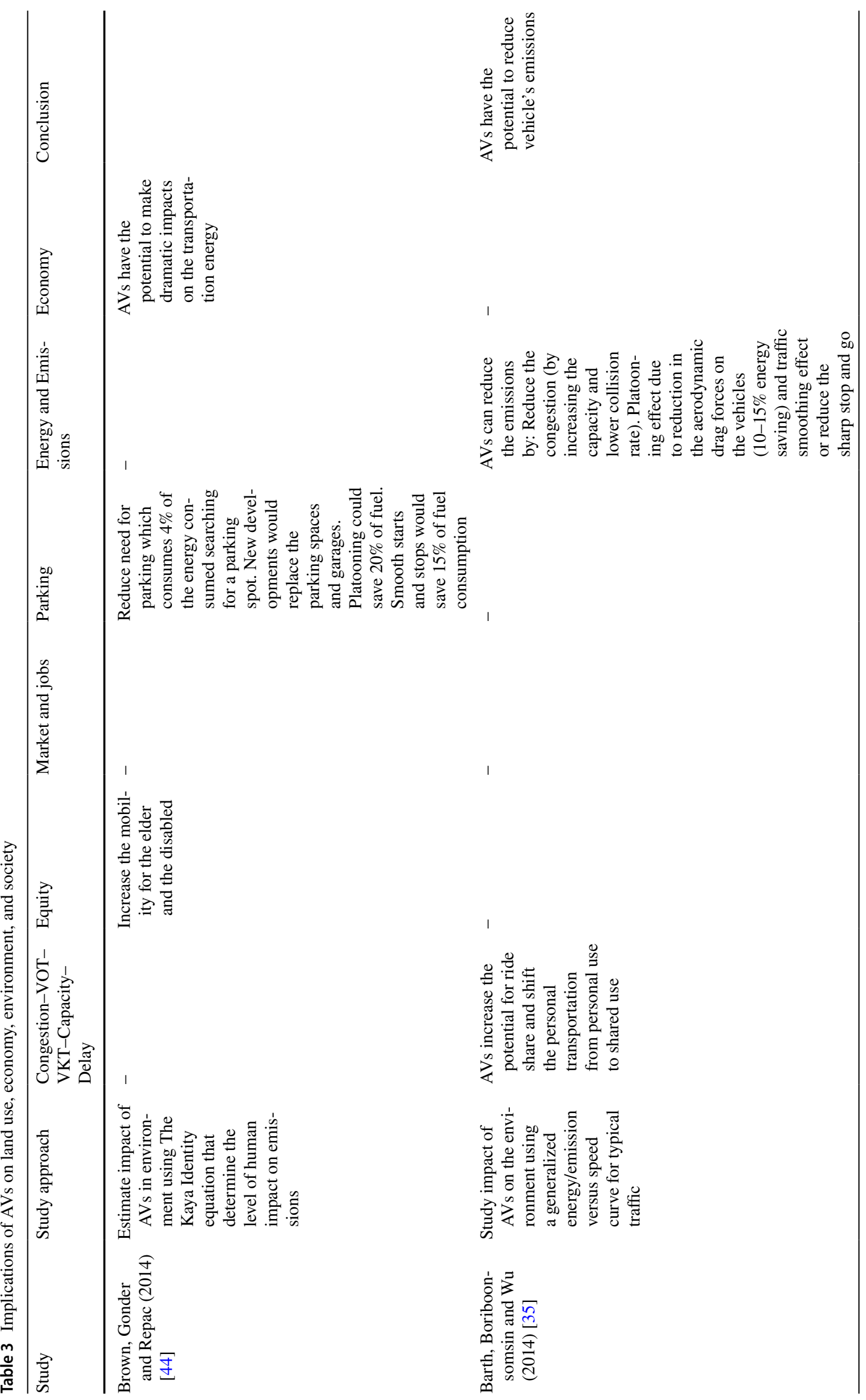




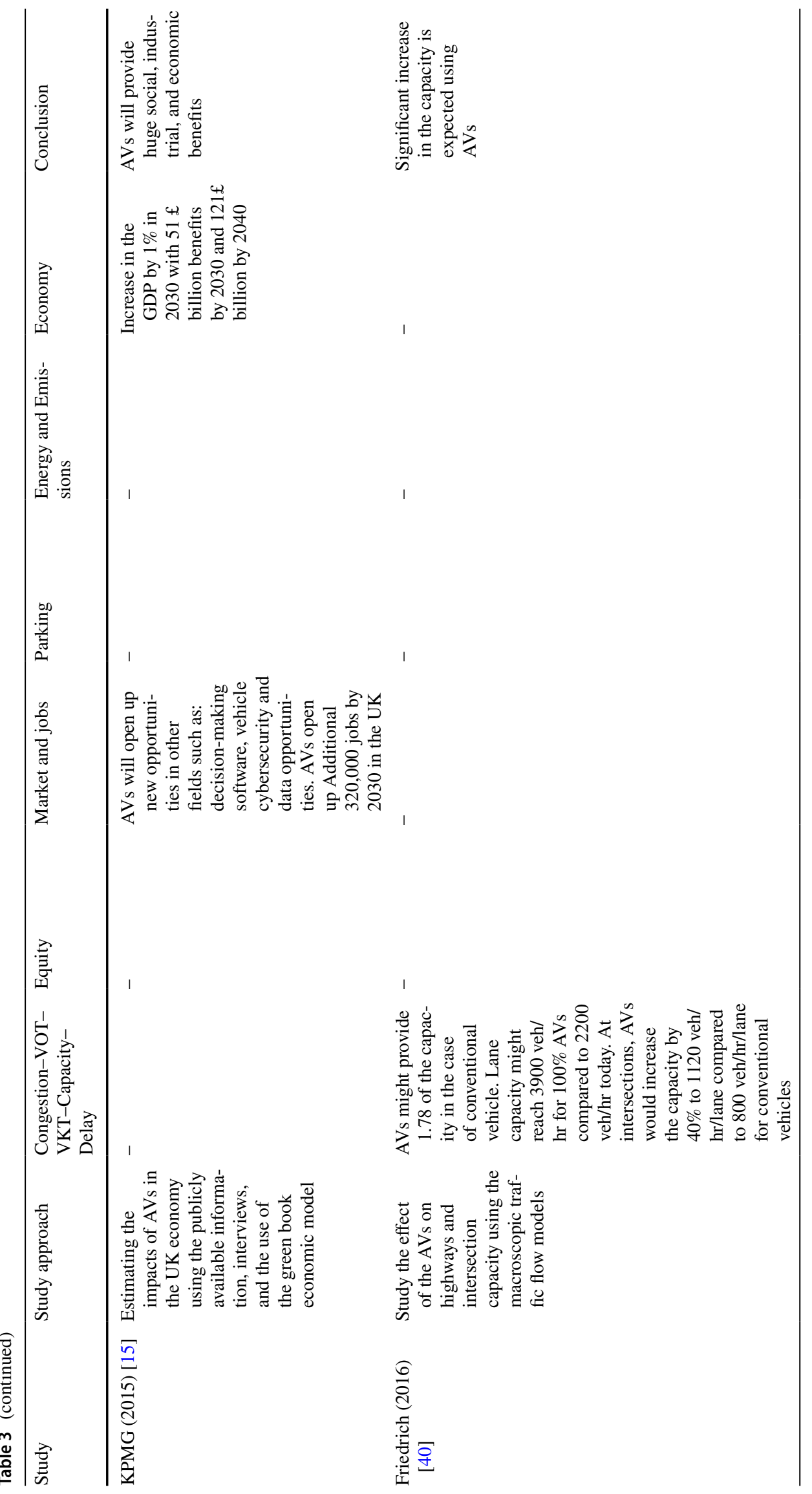




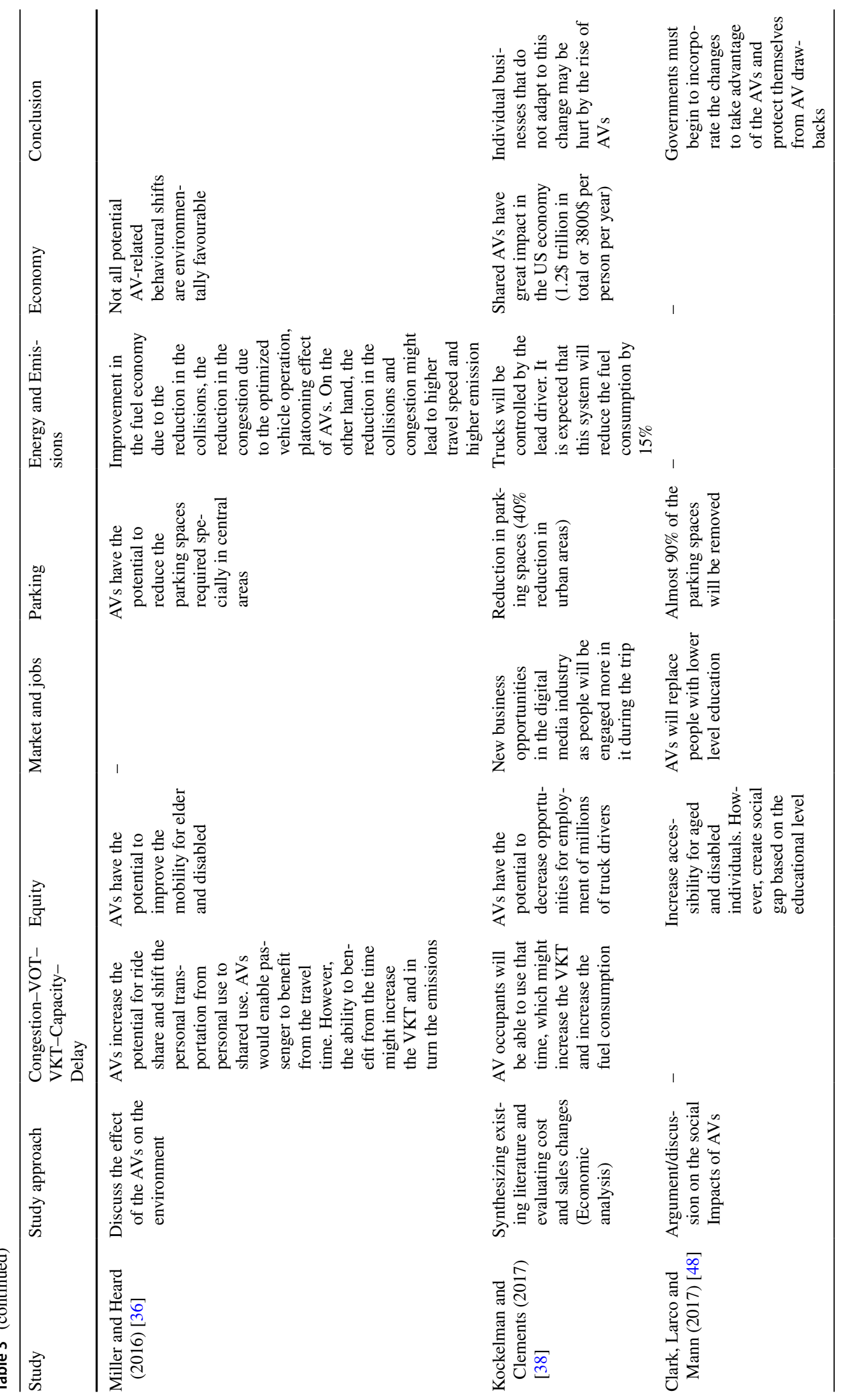




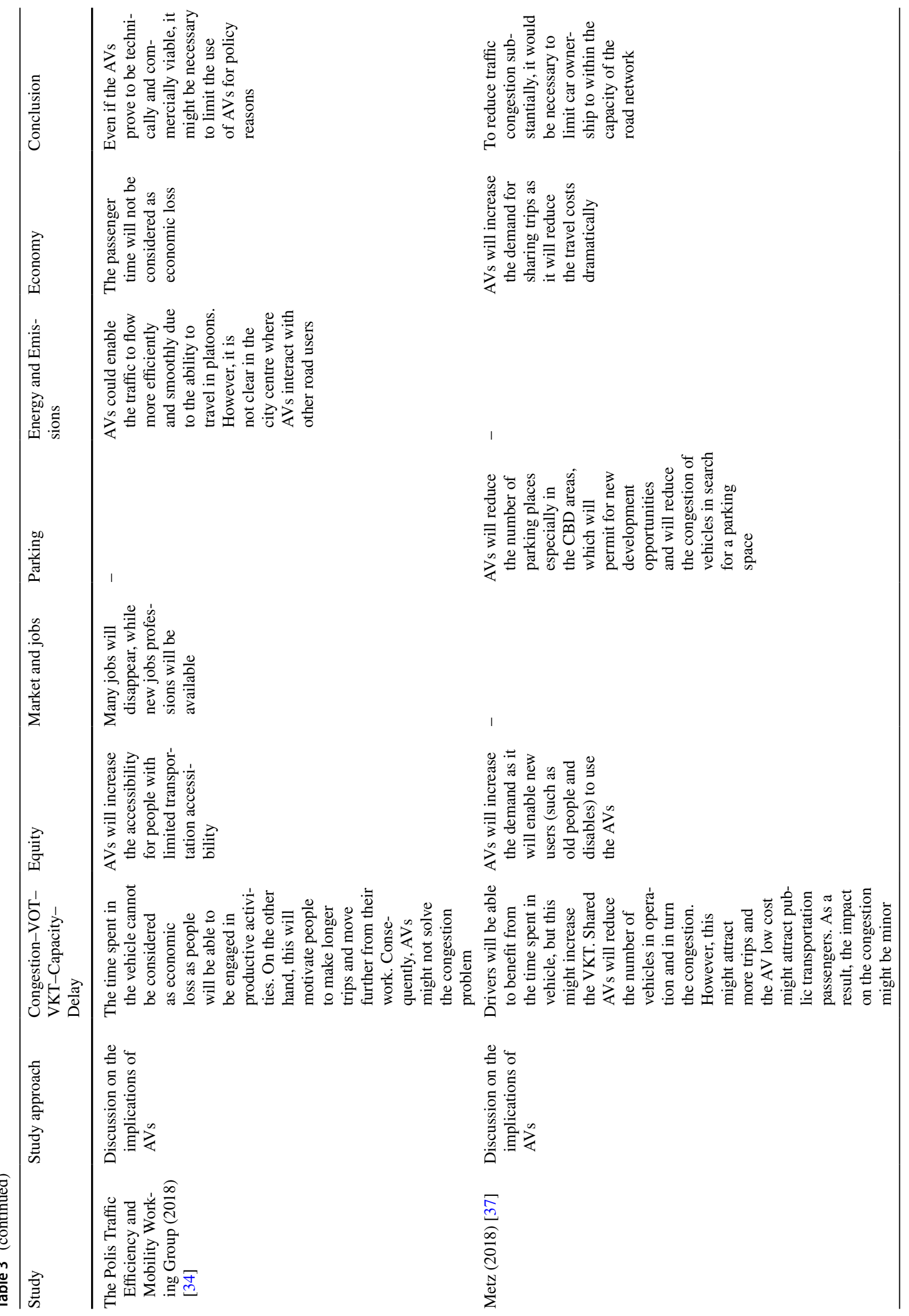




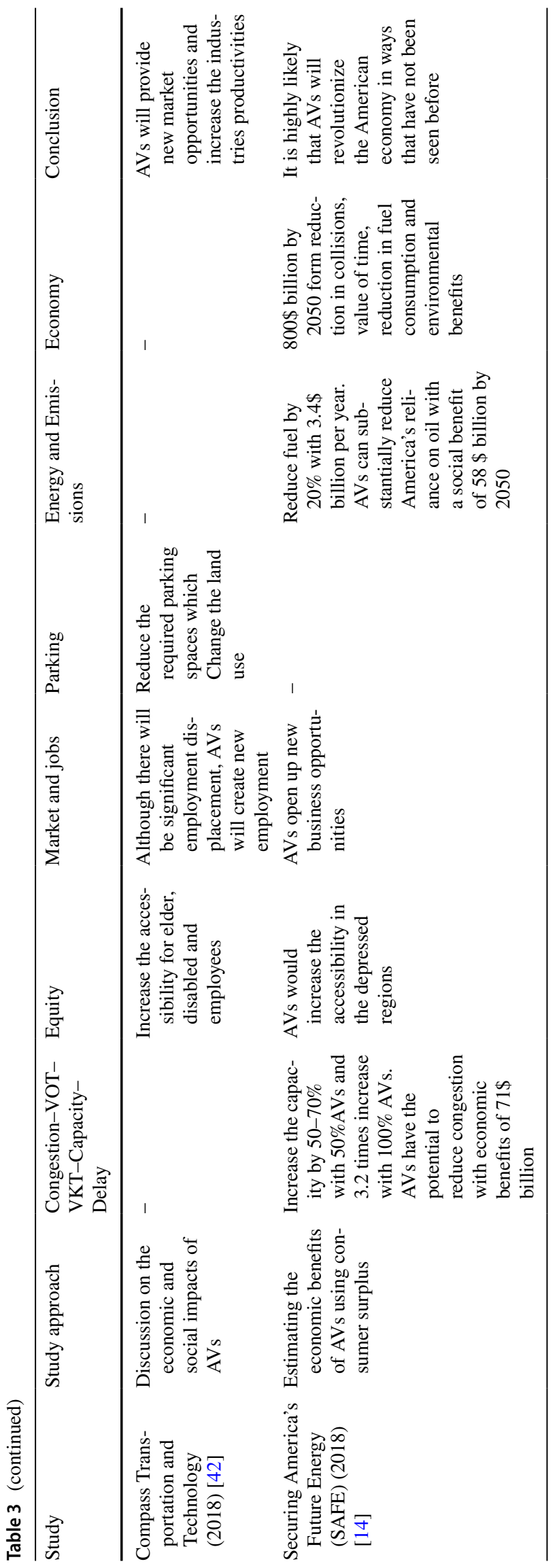

\section{Implications of AVs on vehicle ownership (fleet size) and vehicle utilization}

The adoption of AVs promises many changes. One of these changes is the reduction in the vehicle ownership or increase in the vehicle utilization. Results of previous simulation models show that every single AV can replace a significant number of conventional vehicles, especially if it is used as a shared mode of transportation, which means that a lower fleet size can serve the same population with higher vehicle utilization $[14,15]$. Studies show significant increase in vehicle utilization from $5 \%$ in conventional vehicles [16] up to 75\% [17]. This increase in vehicle utilization is beneficial as it means shorter life span and adaption of newer and better technology [18]. Simulations of $\mathrm{AVs}$ as a shared mode showed that every AV can replace more than 10 conventional vehicles [16-21]. However, using AVs privately showed a slight reduction in the overall vehicle ownership. For example, the simulation model in Germany by Moreno, Michalski, Llorca, and Moeckel (2018) showed that every AV can replace 2.5 conventional vehicles. This is because of the difference in assumptions between this study and all other studies [22]. All the previous studies assumed that all trips will be made by SAVs, but Moreno, Michalski, Llorca, and Moeckel (2018) study [22] mimicked the results of a survey that showed that $24 \%$ of respondents would use shared AVs. Consequently, it is more reasonable to rely on the later results $(\mathrm{AV}=2.5$ conventional vehicles) because it is not realistic to assume that $100 \%$ of the trips will be made by shared AVs (SAVs). Over time, the percentage of trips made in shared AVs might change as AV penetration increases and shared AVs prove their high performance and gains for society then the percentage of shared trips might increase and become closer to the percentages stated in the first studies (AV $>=10$ conventional vehicles). Similarly, Zhang, Guhathakurta, and Khalil (2018) showed that sharing AVs between the same household members reduces the vehicle ownership by $20 \%$, which is also a significant reduction, but modest when compared to other studies [23].

In brief, $A V s$ have the potential to reduce vehicle ownership significantly, even if it used privately. On the other hand, using AVs as a shared mode shows promising results with a significant reduction in the required fleet size to serve the same population. This reduction in fleet size is beneficial for the society and environment because it means lower emissions, better traffic conditions, much higher vehicle utilization, and shorter life span, which in turn means the adoption of newer and cleaner technology quickly.

Singapore provides a realistic example of the potential of AVs to reduce vehicle ownership. Pilot studies in 
Singapore started in 2015 and the city is known as the world's most AV-friendly country. The city allowed for tests in a wide range of autonomous vehicles for private and public use, that more than 10 companies are testing their vehicles in the city. Results showed that by 2018 (in three years) vehicle ownership reduced by $15 \%$ [24].

One major factor that influences the vehicle ownership is regulations. Regulatory action will be a significant determinant of how AVs could affect the ownership. For example, cities might allow AVs as shared mode only and prevent the private use. Currently, cities focus on testing AVs as a shared mode. For example, the following cities are testing autonomous shuttles or autonomous buses: Texas-USA, Wageningen — the Netherlands, Helsinki-Finland, Paris-France, Shenzhen - China, Sion—Switzerland, Edmonton—Canada. Using AVs as a shared mode of transportation guarantees the maximum benefits.

\section{Quality of the service (waiting time and travel cost) provided by shared AVs (public transit vs. AVs)}

Although shared AVs reduce the required fleet and significantly increase the vehicle utilization, it provides high-quality service for the public. One important factor for travellers in shared transportation modes is the average waiting time because people perceive their waiting time considerably much longer than the actual time. Different surveys provided different waiting time to in-vehicle time ratios [25].
For example, Wardman (2004) found that one-minute waiting is equivalent to $2.5 \mathrm{~min}$ of in-vehicle time [26]. Horowitz (1981) found that the ratio is 1.9 [27]. Abrantes and Wardman (2011) found that one-minute waiting is equivalent to $1.4 \mathrm{~min}$ in vehicle [28]. Consequently, any reduction in passenger waiting time has a significant influence on customer satisfaction. Currently, the average transit waiting time in the USA is approximately $40 \mathrm{~min}$ (31\% of their commuter time) $[29,30]$. The average waiting time in Toronto, Canada, is $20 \mathrm{~min}$ [31].

For the case of shared AVs, results show that shared AVs can provide significantly lower waiting time ( $5 \mathrm{~min}$ on average) when compared with the current transit waiting time and with significantly lower trip costs as shown in Table 4.

In conclusion, shared AVs have the potential to significantly reduce the average waiting time and trip costs when compared with the current transit service, which means that shared AVs will be a strong competitor to the transit service and might attract public transit users. Thus, transit agencies should be aware of this new coming disruption to the transportation system or else they will incur significant losses; in particular, AVs will be available sooner or later.

\section{Implications of AVs on the public behaviour}

One of the biggest advantages of AVs is that passengers will be able to be engaged in other activities, which in turn means that the trip time will not be considered as economic loss [34]. Additionally, AVs have the potential for ridesharing

Table 4 Summary of the studies investigating the waiting time and trip costs of SAVs

\begin{tabular}{|c|c|}
\hline Simulation study & Results \\
\hline Burns, Jordan, and Scarborough (2012) [17] & $\begin{array}{l}\text { The simulation model for Ann Arbor, Michigan, USA, to achieve a customer waiting time of two } \\
\text { minutes or lower shows high-cost reduction from } 21 \$ \text { to } 2 \$(90 \% \text { reduction) per day due to } \\
\text { reduction in the ownership cost, operating expenses, parking fees and value of time }\end{array}$ \\
\hline Burns, Jordan, and Scarborough (2012) [17] & $\begin{array}{l}\text { Two simulation models for Babcock Ranch, Florida, USA, and Manhattan, New York, USA, } \\
\text { showed radically low trip cost with a waiting time less than two minutes. In Manhattan, results } \\
\text { show high-cost reduction from } 7.8 \$ \text { per trip (using the traditional yellow taxi) to } 0.8 \$ \text { per trip } \\
\text { ( } 88 \% \text { reduction) due to the reduction in the ownership cost, operating expenses, and central } \\
\text { coordination. For the Babcock Ranch case, the mobility service cost would be less than } 3 \$ \text { per } \\
\text { day per person or } 1 \$ \text { per trip }\end{array}$ \\
\hline International Transport Forum [16] & $\begin{array}{l}\text { The simulation model for Lisbon, Portugal, shows that AVs can provide an average waiting time of } \\
3.7 \text { min }\end{array}$ \\
\hline Zhang, et al. (2015) [19] & $\begin{array}{l}\text { A simulation model for the City of Atlanta, USA, shows that AVs can provide an average waiting } \\
\text { time of } 0.12 \mathrm{~min}\end{array}$ \\
\hline Azevedo L, et al. (2016) [32] & The simulation model for Singapore shows that AVs can provide an average waiting time of 3 min \\
\hline Bischoff, and Maciejewski (2016) [20] & $\begin{array}{l}\text { The simulation model for Berlin, Germany shows that AVs can provide an average waiting time of } \\
2.5 \text { min and up to } 5 \text { min during the peaks }\end{array}$ \\
\hline Hörl, Erath, and Axhausen (2016) [33] & $\begin{array}{l}\text { The simulation model for the City of Sioux Falls, USA, shows that AVs can provide an average } \\
\text { waiting time of } 5 \text { min during the off-peak and an average waiting time of } 10 \text { to } 15 \text { min during the } \\
\text { peak periods }\end{array}$ \\
\hline Moreno, et al. (2018) [22] & $\begin{array}{l}\text { The simulation model for greater Munich metropolitan area, Germany shows an average waiting } \\
\text { time of } 5 \text { min with } 95 \% \text { of the waiting time is lower than } 10 \mathrm{~min}\end{array}$ \\
\hline
\end{tabular}


and shifting the personal transportation from personal use to shared use [35, 36] as discussed in Sect. 4 (Implications of AVs on Vehicle ownership (Fleet size) and vehicle utilization). This reduction in fleet size means better traffic conditions and mitigation of congestion. On the other hand, AVs will motivate people to make longer trips, travel further, and make additional trips which in turn increase the VKT [34, 37]. The increase in the VKT increases the emissions [36] and fuel consumption [38]. Results of AV simulation models show that AVs have the potential to significantly increase the VKT for a variety of reasons as shown in Table 5.

Additionally, while the mentioned simulation models show that AVs have the potential to increase the VKT, all these studies do not take into account the possibility that AVs might motivate people to make additional trips. Thus, it must be mentioned that the low waiting times and low trip costs of AVs might attract people to make additional trips (induced demand) and might discourage people from making trips using public transportation [37], which in turn means a significant increase in the VKT, and emissions. Moreover, this additional demand besides with the increase in the VKT might worsen the traffic conditions. Thus, AVs might not solve the congestion problem, but as mentioned before the time spent in the vehicle will not be considered as an economic loss [34] as passengers will spend their time in productive activities. In conclusion, while AVs have the potential to allow people to be engaged in productive activities during their trips (good influence from the economic perspective), AVs have the potential to motivate people to make additional trips which significantly increase the VKT and emissions (bad influence from the environmental perspective). Thus, while AVs might enhance the economic condition, they might destroy the environment. One major factor that has an impact on the public behaviour is regulations. Regulatory action will be a significant determinant on controlling the change in the public behaviour and in turn the impact of AVs. For example, regulations might allow AVs as a first mile-last mile solution to support public transit service, which guarantees the maximum benefits of AVs.

\section{Implications of AVs on capacities of roads and intersections}

AVs have the potential to reduce the distance between the vehicles (distance ahead) and to reduce the lane width [40] due to the high level of communication between vehicles and the elimination of human factors from the driving process, which in turn means a significant increase in capacity of roads as shown in Table 6 .

In conclusion, $\mathrm{AVs}$ have the potential to increase roads and intersection capacities. On the other hand, it is not expected that this increase can be achieved until a high level of market penetration [37] as with conventional driving the human factor will dominate for safety issues or for human feeling of safety as people will be sacred to see the vehicle drive close to the vehicle ahead or the vehicle beside. However, in AVs, people might be involved in other activities (sleeping, watching movies, or any other activity) and probably they will not see the surrounding roads, which might allow vehicles to drive close to each other.

\section{Implications of AVs on the land use}

AVs will change more than our streets, over time they could change the structure of cities, towns, and neighbourhoods. For example, AVs have the potential to reduce the number of parking spaces needed to serve the population. These freed-up spaces can be used for other purposes and allow for the construction of new developments. Results of the previous simulation models show that AVs have the potential to

Table 5 Summary of the studies investigating the impact of AVs on the public behaviour

\begin{tabular}{|c|c|}
\hline Study & Results \\
\hline Fagnant and Kockelman (2014) [18] & $\begin{array}{l}\text { The simulation model for Austin, Texas, USA, shows an increase in the VKT by } 11 \% \text { due to } \\
\text { vehicle relocation searching for cheap parking lots during the low demand periods }\end{array}$ \\
\hline International Transport Forum [16] & $\begin{array}{l}\text { The simulation model for Lisbon, Portugal, shows an increase of } 6 \% \text { in the VKT with } 50 \% \text { AVs } \\
\text { and } 89 \% \text { increase in the VKT with } 100 \% \text { AVs }\end{array}$ \\
\hline Hörl, Erath, and Axhausen (2016) [33] & The simulation model for the City of Sioux Falls, USA, shows $60 \%$ increase in the VKT [33] \\
\hline Zhang, and Guhathakurta (2017) [39] & $\begin{array}{l}\text { Zhang and Guhathakurta (2017) studied the impact of parking prices on the VKT for the City } \\
\text { of Atlanta, USA, using simulation models for three scenarios: free parking (as a baseline), } \\
\text { entrance-based charge, and time-based charged. AVs were programmed to reduce their overall } \\
\text { costs (travel or fuel costs and parking costs). Results showed } 5 \% \text { increase in the VKT for the } \\
\text { case of entrance based and 14\% increase in the VKT for the time-based parking [39]. Thus, } \\
\text { the parking strategy has a significant impact on the VKT }\end{array}$ \\
\hline Zhang, Guhathakurta, and Khalil (2018) [23] & $\begin{array}{l}\text { The simulation model for the Atlanta Metropolitan Area, USA, based on the assumption that } \\
\text { Vehicles will be shared within the same household members shows an increase of } 13.3 \% \text { in } \\
\text { the VKT }\end{array}$ \\
\hline
\end{tabular}


significantly reduce the parking demand and required parking lots as shown in Table 7.

Furthermore, AVs might change the design of parking lots. Theoretical speaking, AVs will park themselves without the need for the door space which could enable $20 \%$ more free spaces. Moreover, AVs can block each other and let each other out when necessary as shown in Fig. 1. A study by Audi suggested that a parking space can take 2.5 times the conventional vehicles using this blocking method [43]. Thus, AVs have the potential to significantly reduce the number of parking places required in the CBD areas [36], which reduces congestion of vehicles in search for a parking space [37], that consumes $4 \%$ of the energy (fuel) consumed [44]. Additionally, the freed-up parking spaces can be used for other purposes. For example, using the parking areas in the real estate industry can increase the value of land use by 5\% [38]. In addition, AVs will not rely on on-street parking but will travel to the nearest off-street parking. Thus, AVs can increase the road capacity as these parking lanes can be used to serve the traffic. Moreover, this reduction in the parking demand might be also associated with changes in houses design as the end house parking spaces might not be needed anymore and can be used for other purposes. In other words, AVs can indirectly increase the areas of houses.

Table 6 Summary of the studies investigating the impact of AVs on the road and intersection capacity

\begin{tabular}{|c|c|}
\hline Study & Results \\
\hline Friedrich (2016) [40] & $\begin{array}{l}\text { The study analysed the impact of AVs on road capacity using the macroscopic traffic flow models. Results showed } \\
\text { that AVs with } 100 \% \text { market penetration might provide } 1.78 \text { of the capacity of the traditional vehicles with a lane } \\
\text { capacity of } 3900 \mathrm{veh} / \mathrm{hr} \text { compared with } 2200 \mathrm{veh} / \mathrm{hr} \text { for conventional vehicles. Additionally, AVs might increase } \\
\text { the intersection capacity by } 40 \%\end{array}$ \\
\hline Wagner (2016) [41] & $\begin{array}{l}\text { This study estimated the impact of AVs at the intersection level in Braunschweig, Germany using a simulation } \\
\text { model for intersections and a simulation of a green wave. Results showed that AVs can double the capacity at } \\
\text { intersections and AVs can improve the delay times in the case of sub-optimal coordination because the number } \\
\text { of vehicles leave a signal is much more when compared with the case of human drivers. Consequently, AVs can } \\
\text { reduce the delays dramatically up to } 80 \%\end{array}$ \\
\hline $\begin{array}{l}\text { Securing America's Future } \\
\text { Energy (SAFE) (2018) } \\
\text { [42] }\end{array}$ & $\begin{array}{l}\text { This study estimated that AVs can increase the capacity by } 50 \% \text { to } 70 \% \text { with } 50 \% \text { AV market penetration and } 320 \% \\
\text { increase with } 100 \% \text { AV market penetration }\end{array}$ \\
\hline
\end{tabular}

Table 7 Summary of the studies investigating the impact of AVs on the land use

\begin{tabular}{ll}
\hline Study & Results \\
\hline Fagnant and Kockelman (2014) [18] & $\begin{array}{c}\text { An agent-based model for Austin Texas, USA, shows that each AV can remove 11 parking spaces com- } \\
\text { pared with the case of conventional vehicles } \\
\text { The simulation model for the city of Atlanta, USA, which is based on the assumption that 2\% of the } \\
\text { population are using AVs shows 90\% reduction in the parking demand for the served population } \\
\text { Thang et al. (2015) [19] }\end{array}$ \\
$\begin{array}{c}\text { The simulation model for Lisbon, Portugal, shows that AVs can alter the need for the on-street parking } \\
\text { and free up an area of almost 1,153,000 m2 which represents almost 20\% of the overall area of streets } \\
\text { in the city of Lisbon. Moreover, AVs might make it possible to remove 80\% of the off-street parking }\end{array}$ \\
$\begin{array}{c}\text { The simulation model for the city of Atlanta, USA, which is based on the assumption that only 5\% of the } \\
\text { residents would use AVs instead of their conventional vehicles shows 4.5\% reduction in the parking } \\
\text { demand which can be translated into 90\% reduction in the parking demand for the served population }\end{array}$ \\
\hline
\end{tabular}

Fig. 1 Traditional parking strategy for human-driven vehicles vs. the blocking parking strategy for AVs

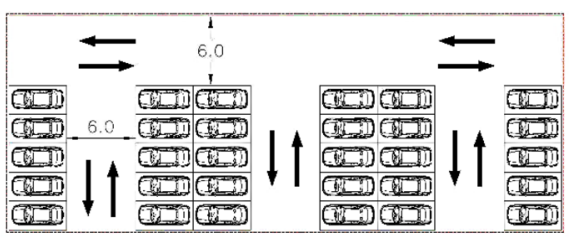

Traditional parking strategy for human-driven vehicles (for 30 vehicles)

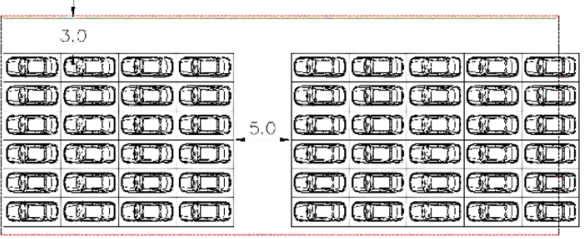

Blocking parking strategy for AVs (54 vehicles on the same parking area) 


\section{Implications of AVs on the energy consumption and emissions}

Transportation is the main source of pollution on our planet. Transportation contributed to $29 \%$ of greenhouse gas emissions in the USA in 2017. It was found that the transportation sector generates the largest share of greenhouse gas emissions that are primarily generated from the following sources: burning fossil fuel for cars, trucks, ships, trains, and planes. More than $90 \%$ of the fuel used in transportation is petroleum-based, which includes primarily gasoline and diesel [45]. Additionally, it was estimated that road transport contributes to $72 \%$ of the total transportation pollutions. Cars alone contribute to $44 \%$ of the $72 \%$ [46]. In Canada, transportation contributes to $25 \%$ of the total emissions [47]. Consequently, transportation is the main source of pollution and the search for a sustainable transportation system became critical, and a wide area of research. Previous simulation models show that AVs have the potential to provide a sustainable transportation system and significantly reduce energy and emissions as shown in Table 8.

In summary, AVs enable high levels of communication between vehicles, which allow vehicles to travel in platoons. Platoons can reduce $15 \%$ of the fuel used [35, 38 ] or up to $20 \%$ [14]. Additionally, AVs make it possible to apply the vehicle optimal traffic assignment to minimize the total travel time and in turn optimize the fuel consumed and reduce the emissions [36]. Moreover, AVs smooth starts and stops can save $15 \%$ of fuel consumption.

\section{Implications of AVs on the economy}

It is expected that the impact of AVs will extend beyond the simple crash, and fuel saving into every aspect of the economy. Businesses companies that are unable to adapt to this change may be hurt by the introduction of AVs. For example, AVs will increase the demand for sharing trips and so it will reduce the travel costs dramatically [37]. In the worst case, AVs might not solve the congestion problems as the additional demand and increase in VKT might offset the increase in the capacity. However, the drivers' time will not be considered as an economic loss anymore as drivers can spend their trips in productive activity [34, 38].

Kockelman and Clements (2017) studied the impact of AVs on the economy of the USA. For software and technology companies, AV software technology is expected to grow from $680 \$$ million in 2025 to $15.8 \$$ billion in 2040 . Also, the required mapping process is expected to grow from $530 \$$ million to $10.6 \$$ billion in 2040 . This contributes to revenue of $26.4 \$$ billion in 15 years. Moreover, the impact on health care will be enormous. Based on NHTSA 2015, accidents account for $23 \$$ billion as medical expenses in the USA. As a result, assuming $90 \%$ reduction in collision rate (due to the elimination of the human error) means a reduction of 20.7 $\$$ billion each year, a reduction in the need for supplies and

Table 8 Summary of the studies investigating the impact of AVs on the environment

Study Results

Barth, Boriboonsomsin, and Wu (2014) [35]

This research studied the impact of AVs on energy consumption and emissions using the generalized energy or emission versus speed curve for typical traffic which state that the lowest emissions level and the lowest fuel consumption level occur at a speed range between 35 and $55 \mathrm{mph}$. Results shows that AVs can reduce emissions and energy through three main factors: first, reducing congestion (by increasing the capacity and reducing collision rate) and in turn increase the speed. Second, vehicle platoons which reduce the aerodynamic drag forces on vehicles as a separation of $4 \mathrm{~m}$ can achieve $10-15 \%$ energy saving. Third, traffic smoothing effect that reduces the sharp stop and go. The smooth operating can reduce the fuel consumption by $15 \%$

Fagnant and Kockelman (2014) [18]

Miller and Heard (2016) [36]

Kockelman and Clements (2017) [38]

Securing America's Future Energy (SAFE) (2018) [42]
The simulation model for Austin, Texas, USA, shows 34\% reduction in the CO2 emissions and $49 \%$ reduction in the volatile organic compounds (VOC)

Results shows that AVs can enhance the fuel economy dramatically due to: platooning effect, reduction in collisions, and reduction in congestion due to the optimized vehicle operation as AVs will allow for the application of system optimal traffic assignment which reduces the total travel time in the entire network. On the other hand, reducing collisions and congestion might increase the travel speeds, which means higher emission

This study estimated that AV platooning can improve safety and reduce the fuel consumption by $15 \%$

Results of this study show that AVs can reduce the fuel consumed by $20 \%$ with an economic benefit of $3.4 \$$ billion per year. Additionally, AVs can substantially reduce America's reliance on oil with a social benefit of 58 \$ billion by 2050 
doctors, and better allocation of personnel to provide better services. Additionally, AVs will increase the value of land use as the land used as parking before can be converted into houses, parks, or other developments. The average value of a parking place in the USA is $6300 \$$ with a total value of all parking spaces of $4.5 \$$ trillion. However, using the parking areas in the real estate industry will increase the land use value by $5 \%$. The study concluded that Shared AVs have a great impact on the economy (1.2\$ trillion in total or $3800 \$$ per person per year) [38].

Compass Transportation and Technology (2018) evaluated the impact of AVs on the economy of the USA. Results show that the benefits to cost ratio of the AVs is $8: 1$. Additionally, an improvement of $10 \%$ in the transportation network is associated with a two per cent (or a bit more) improvement in overall economic productivity or improvement in GDP [42]. Securing America's Future Energy (SAFE) (2018) studies that the impact of AVs on the economy of the USA. Results show that the reductions in collisions, the value of time, fuel consumption, and environmental benefits will contribute to benefits of almost $800 \$$ billion by 2050 [42]. Additionally, KPMG (2015) examined the impact of AVs on the UK economy. Results show that the economic and social benefits of the AVs can reach $51 £$ billion by 2030 ( $1 \%$ increase in GDP) and $121 £$ billion by 2040 [15].

\section{Implications of AVs on the society (equity)}

AVs have the potential to increase coverage and accessibility for aged and disabled individuals [14, 36, 42, 44, 48]. Additionally, AVs can increase the accessibility for people with limited transportation accessibility [34] such as rural areas or depressed regions [14].

AVs have the potential to radically change the conventional market. Many jobs will disappear, while new job professions [34] and new business opportunities [14] will be available. AVs open new opportunities in a variety of fields such as decision-making software, vehicle cybersecurity, and data opportunities. AVs will provide new opportunities for the digital media as commuters who are used to watch the road will switch to use the digital media features in their automobiles during their trips. Additionally, Internet shopping could receive a large bump from this added free time. It is estimated that AVs will provide 320,000 additional jobs in the UK [15]. On the other hand, this increase in entertainment flexibility for passengers might reduce the use of radio as people might prefer other activities to do while in the vehicle [38].

On the other side, people are likely to be replaced by AVs, which have a potentially significant impact on individuals with lower levels of education and income and consequently implications and concerns for equity [48]. AVs can cause serious loss for truck drivers as the technology would reduce the opportunity for the employment of millions of drivers [38]. On the other hand, a recent study by Gittleman and Monaco (2020) shows the risk on truck drivers is real, but the projections touted are overstated because companies will not be able to abandon all drivers as drivers do more than just driving and not all the tasks can be automated [49]. For example, checking for safety problems can be performed by sensors, but AVs cannot fix these issues so dealing with these detected issues requires human interaction.

\section{Implications of AVs on the public health}

Implications of AVs on public health could vary depending on many factors such as the type of use or ownership, automation level, and the type of engine such as internal combustion, and hybrid engines. While AVs might increase some risks such as pollution and sedentarism, $\mathrm{AVs}$ might reduce morbidity and fatalities from vehicle collisions and might help reshape cities to promote healthy environments. Public health can benefit from the proper regulations if these regulations are implemented before the introduction of AVs in the market. This section explores the benefits and risks of AVs on the public health.

\section{Physical activity}

Physical activity related to transportation has been suggested as a main source or strategy for increasing the daily physical activity level [50-52]. The benefits of this active transportation have been recognized in many cities around the world and have shown direct and indirect benefits such as the reduction the noise level and the improvement in the air quality. While it is difficult to predict the impact of AVs on the travel behaviour and their impact on the physical activities, AV simulation models suggest that AVs could increase the VKT to pick up passengers from their location and in turn reduce the physical activity [53]. Additionally, privately owned AVs might lead to a more dispersed urban growth pattern (sprawl), which in turn increases the average trip length and discourages people from walking or cycling [54]. On the other hand, if people are willing to share their trips, shared AVs could reduce the VKT when compared to private AVs. Thus, shared AVs are likely to increase the physical activity more than privately owned AVs because this approach needs to be complemented by walking, cycling, or using public transportation. 


\section{Air pollution and emissions}

It was estimated that around $95 \%$ of the world's population lives in areas that exceed the healthy air requirements provided by the World Health Organization (WHO) [55]. Motorized vehicles are one of the main sources of air pollution [56, 57]. In 2015, it was estimated that 250,000 deaths were related to air pollution from road transportation [58]. Emissions related to transportation can be classified into two categories: exhaust emissions and non-exhaust emissions.

\section{Exhaust emissions}

Three main factors have a strong influence on the implications of AVs on the air pollution as follows: the implications of AVs on the VKT, the reliance on gasoline engines or electric vehicles, and the integration between AVs and public transportation or active transportation modes [51]. Simulation models show that $\mathrm{AVs}$ have the potential to increase the VKT and thus increase the air pollution exposure. Additionally, as gasoline and diesel engines pollute more than electric vehicles do, if AVs are not fully electric, travellers would be exposed to higher pollution levels, and higher air pollution exhaust emissions would then affect the public health. Finally, AVs can increase the air pollution level if AVs use patterns do not facilitate walking, cycling, and transit use. Regulations can play an essential role in the implications of AVs on the air pollution and account for these issues to reduce the negative externalities of motorized transport.

\section{Non-exhaust emissions}

Other sources of air pollution sources include brake and tyre wear, road surface wear, and resuspension of road dust. These emissions together might exceed the tailpipe emissions at least in terms of particulate matter [56]. Additionally, bake and tyre wear have higher oxidation potential when compared to other traffic-related sources, which can be translated into worse environmental conditions. Moreover, as the weight of electric vehicles is more than the weight of non-electric vehicles, electric vehicles have the potential to emit more non-exhaust emissions [59]. Thus, AVs have the potential to increase the non-exhaust emissions, even with a shift to electric vehicles, because of the increase of the VKT [60].

\section{Noise}

Noise associated with traffic has been addressed as a source of multiple health issues such as including sleep disturbance, annoyance, cardiovascular disease, and hypertension [61, 62]. In Europe, it is estimated that noise causes 10,000 premature deaths per year $[63,64]$. AVs using internal combustion engines similar to conventional vehicles could continue to contribute more to road traffic noise. As in the case of air pollution, if $\mathrm{AV}$ use results in increasing the VKT, then the noise exposure level would increase [53]. On the other hand, the use of electric vehicles would reduce the noise level considerably. However, at speeds higher than $50 \mathrm{~km} / \mathrm{hr}$ electric vehicles and conventional vehicles produce the same noise levels. For example, a Dutch study estimated that a fleet of fully electric vehicles could reduce the urban noise levels significantly by $3-4 \mathrm{~dB}$ and reduce annoyance effects by more than 30\% [65]. Thus, electric $\mathrm{AVs}$ can reduce the noise level significantly.

\section{Electromagnetic fields}

Electric and magnetic fields (EMFs) can be defined as invisible areas of energy (also called radiation) that are generated by electricity. Low- to mid-frequency EMFs are in the non-ionizing radiation part of the electromagnetic spectrum and are not known to damage DNA or cells directly. Previous studies evaluated the relation between the exposure to non-ionizing EMFs and the risk of cancer with no conclusive results [66]. On the other hand, a recent study by the US National Toxicology Program on male rates showed a clear relation between the exposure to high levels of radiofrequency, such as that used in $2 \mathrm{G}$ and $3 \mathrm{G}$ cell phones, and the development of heart tumours [67]. AVs rely on multiple technologies that would increase the exposure to the EMFs, which in turn might worsen the public health.

\section{Substance abuse}

In 2019, almost 9.9 million people were reported driving under the influence of drugs [68]. Laws prohibit driving under the influence of drugs or alcohol. These laws together with the social norms have increased the public awareness and discourage people from abusing these substances while driving [69]. It is possible that the widespread of AVs would cause laxity in the public attitude towards drugs. In 2017, Australia's National Transport Commission linked AV passengers with taxi passengers and showed that there might be exemptions from the legal restrictions for AV passengers [70]. Thus, a clear definition of the capabilities and requirements of $\mathrm{AV}$ passengers will need to be addressed and aligned with the future policies. Additionally, the efforts against alcohol and drug abuse should be maintained.

\section{Stress}

Driving has been addressed as a source of health issues. Recent studies show that driving for long hours causes a high level of stress [71]. It was found that stress has adverse impacts on the immune, cardiovascular, and nervous systems, among others 
[72]. AVs have the potential to decrease the mental workload and stress, thereby producing a more positive set of emotional responses. Thus, AVs could reduce the stress of driving, and enhance the public health.

\section{AVs and pandemics}

The global COVID-19 has made radical changes in our world, as people had to adapt to a new lifestyle. Experts believe that this pandemic is a turning point that will accelerate the new digital revolution. Although the pandemic has halted many AV pilot studies [73, 74], it is expected that this crisis will accelerate the introduction of AVs as AVs can be useful in emergencies and pandemics as follows:

During the COVID-19 pandemic, China used autonomous vans for food and medical supplies delivery and sanitize streets [75]. In Beijing, a partnership between Neolix and Apollo was established with the aim of delivering food and medical supplies [76]. Similarly, in Florida, USA, the Mayo Clinic has started using the AV developed by Beep to transport COVID-19 tests from the testing site to the processing laboratory [77]. Thus, AVs have proved their value in fighting pandemics so, in the future, AVs can be used as a transportation mean to transport people to grocery stores, healthcare, and pharmacies, while maintaining isolation and sterilization [74, 75].

Vayyar, which is a start-up company, is working on developing new smart vehicles that monitor the cleanliness and air quality that measure airborne contaminations for infected passengers. This feature is very useful as it helps in the early detection of infections and diseases [75].

Finally, AVs can be used for the transportation of people during pandemics and replace the public transit service which is a major source for the outbreak of diseases and viruses. In 2018, Goscé and Johansson studies how public transit affects the spread of viruses in London, and they found a correlation between the use of public transport and the spread of diseases [78].

As a result, AVs have proved their ability in addressing some of the biggest challenges confronting societies in pandemics. Thus, the previous use cases show that AVs represent a major tool in the fight against pandemics that AVs can provide effective, and safe mobility to help people to move to their essential activities.

\section{Autonomous vehicles in developing countries}

While most of the previous work focuses on studies from developed countries, this section sheds light on the implications of AVs and the challenges that face AV deployment in developing countries. However, it must be mentioned that rare studies discuss AVs in developing countries and most of these studies focus only on the public attitude towards AVs (discussed in detail in Sect. 14.2). For example, there is no simulation study for AVs in any developing country. One of the main reasons for this lack of studies is the poor infrastructure that does not support the navigation of AVs, which requires huge capital costs or investments to provide a safe infrastructure that supports AV navigation. In this section, a detailed analysis of the infrastructure challenges that face the deployment of AVs in developed countries will be discussed and analysed.

\section{Public attitude towards AVs in developed countries and developing countries}

One of the main studies that tested the public attitude towards AVs in an international level is the study by Kyriakidis, et al. (2015) [79]. This study used an Internet-based survey with 5000 responses from 109 countries to investigate the public acceptance, worries, and willingness to buy partially, highly, and fully automated vehicles. Comparing the results across different countries (in terms of accident statistics, education, and income) shows that people from developed countries are more pessimistic than people from developing countries towards AV adoption. Specifically, respondents from more developed countries are more worried about data transmitting as shown in Fig. 2 that shows the relationship between the Gross Domestic Product (GDP) and the level of comfort towards data transmission. This difference can be explained in terms of the perceived threat level. In general, people from developed countries have more sophisticated computer infrastructure for data misuse that these countries have multiple widely publicized cases, such as some Google cases $[80,81]$ and Facebook cases $[82,83]$, that makes citizens of developed countries may realistically believe that the threat of data misuse exists and is harmful to them. On the other hand, the fatality rates in developing counties are much higher than in developed countries that the current trends indicate that road traffic injuries will become the fifth leading cause of death by 2030 , with the difference between highand low-income countries further magnified [84]. Thus, according to Maslow's hierarchy of needs [85], people in low-income countries are mostly concerned with basic 
Fig. 2 Average level of comfort in transmitting data to tax authorities versus gross domestic product (GDP) for different countries (adopted from [79])

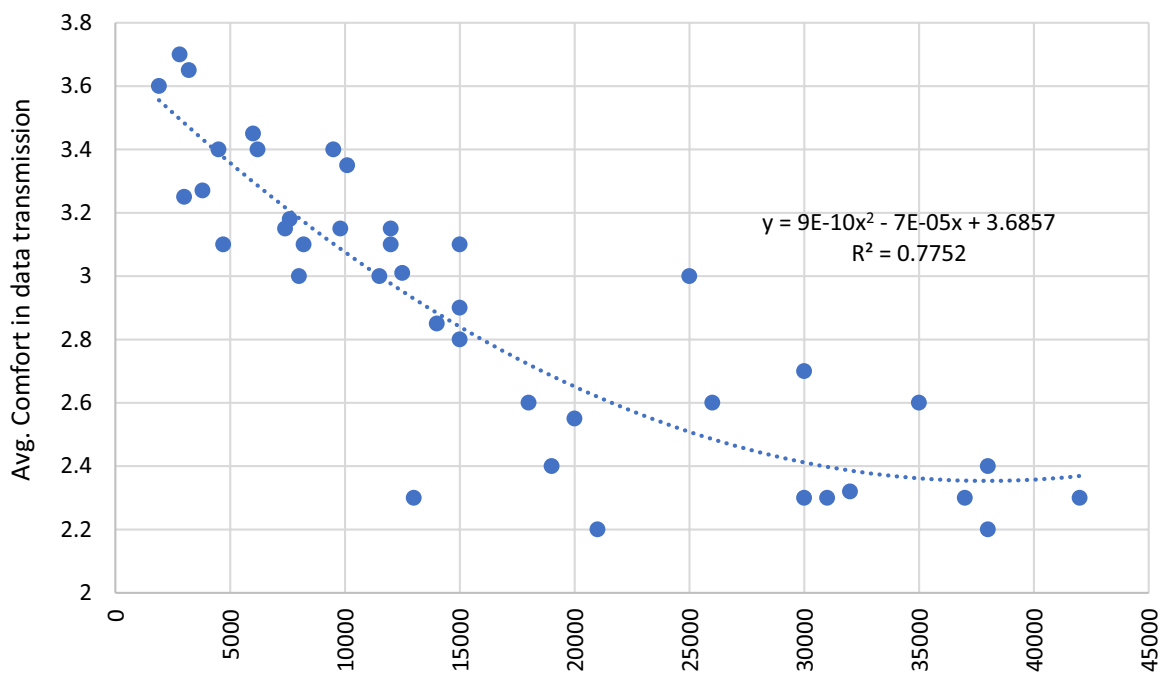

GDP (\$) physiological and safety needs that make data privacy or transmission a least priority issue for them.

Another study by Bazilinskyy et al. (2015) investigated the public attitude towards AVs by analysing textual comments resulting from three international previous surveys with 8,862 respondents from 112 countries and these responses were analysed to understand the difference in the public attitude across different countries. In this study, responses were categorized according to the GDP into three different categories: high-GDP, low-GDP, and medium-GDP. Figure 3 summarizes these results and as shown in the figure people from high-income countries were more likely to express a negative comment and less likely to express a positive comment about automated driving [86] which is compatible with the result of the previous survey by Kyriakidis, et al. (2015) [79].

A third and recent international survey by Moody et al. (2019) with 33,958 respondents from 51 countries investigated public perceptions of AV safety across a diverse sample of individuals from a wide variety of countries. Results show that although respondents from developed countries are more aware of AV technology, they are more pessimistic about the present and future safety of AVs [87]. Figure 4 shows the level of awareness and the public acceptance of AVs in the surveyed countries.
Fig. 3 Percentage of positive and negative comments for different GDP levels (adopted from [86])

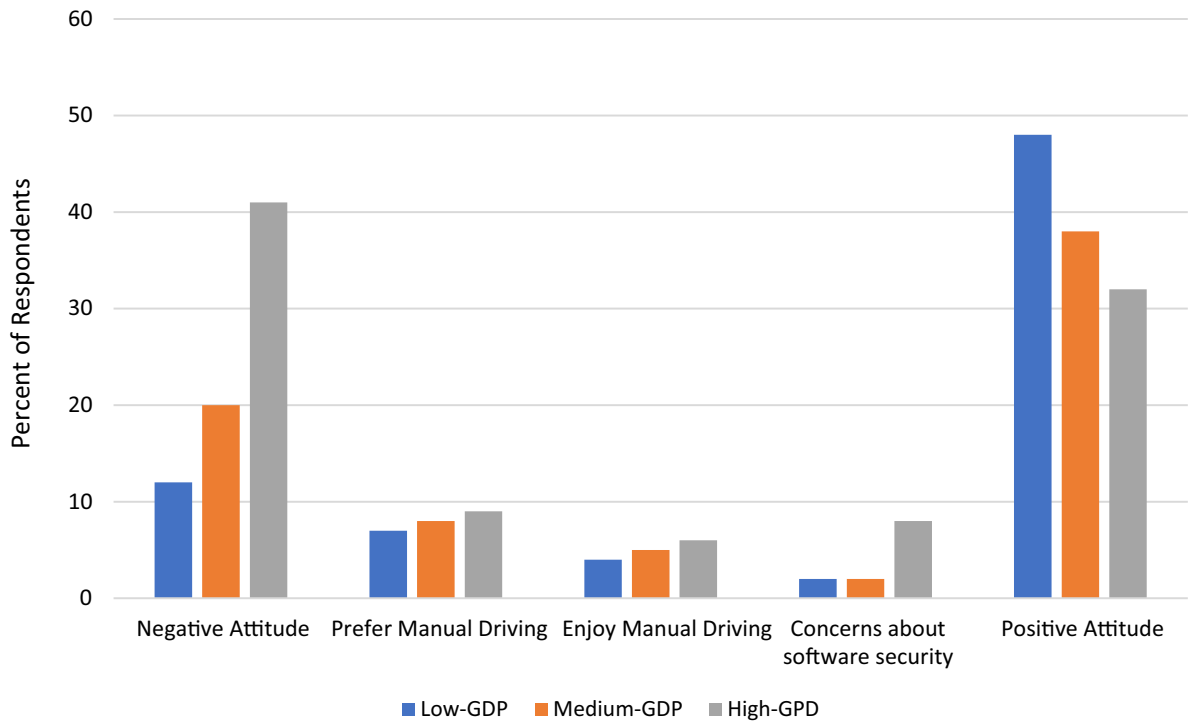


(a)

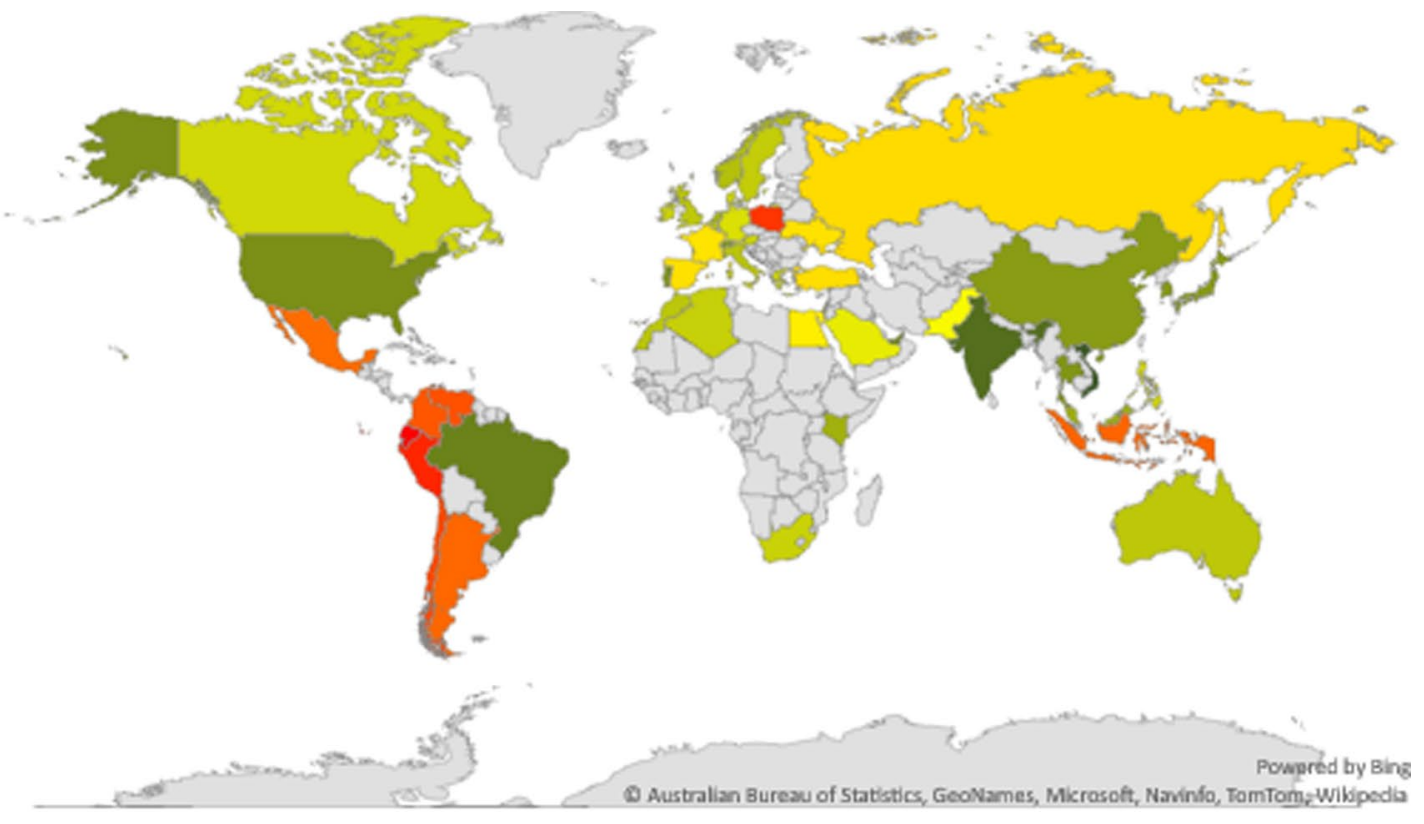

Level of Awarness Awareness

$\begin{array}{lll}-0.764 & -0.063 & 0.638\end{array}$

(b)

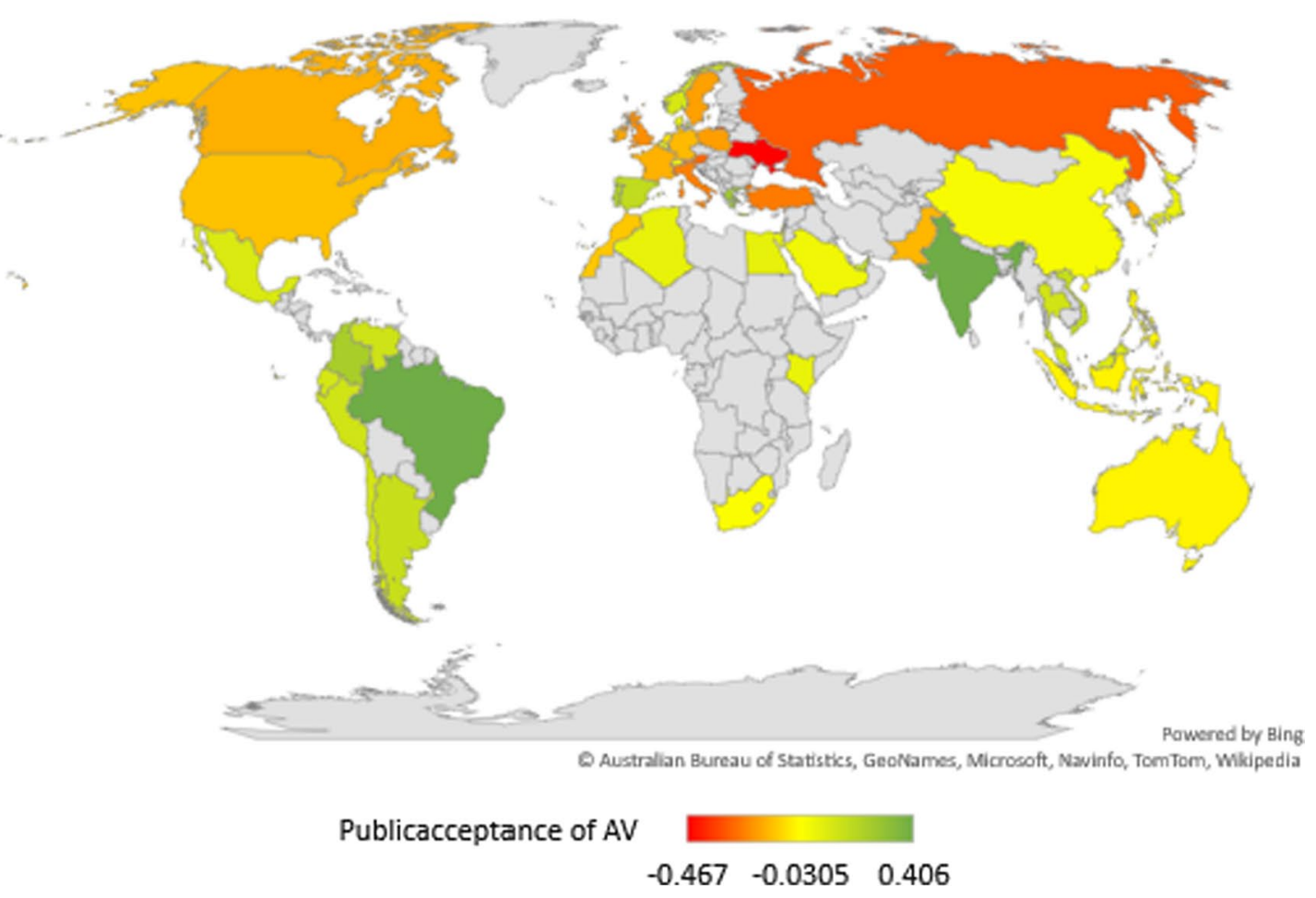

Fig. 4 Different (a) level of awareness and (b) public acceptance of AVs in different countries (adopted from [87]) 


\section{Surveys from developing countries}

In general, the studies that focus on the public acceptance of AVs in developing countries are rare. A recent survey in Pakistan that evaluates the public attitude towards AVs by Shafique et al. (2021) shows that a small proportion of the respondents are not aware of this new technology. Additionally, the main concern of the respondent was not privacy, such as data transmission, but sharing the road space with driverless trucks was the main concern with $70 \%$ of the respondents were highly concerned about the idea of sharing the road with driverless trucks. On the other hand, $15 \%$ of the respondents were highly concerned about the privacy of the vehicle such as the continuous vehicle tracking [88]. Again, these results indicate that safety is the main concern for people in developing countries and privacy is not an issue for them similar to what the previous international surveys show. Additionally, respondents were very optimistic towards AVs as when the respondents were asked about the expected benefits of AVs, $98 \%$ of the respondents believe that AVs can reduce the number of accidents and 99\% believe that AVs can reduce the severity of the crashes. Thus, this high level of trust in AVs' ability to improve traffic safety combined with the non-concerned opinions regarding the privacy or data transmission makes people from developing countries very optimistic towards AVs. The previous statement can be concluded from an earlier survey by Sanaullah, et al. (2017) in Pakistan that shows that Pakistanis are highly interested in AVs. This survey shows that $75 \%$ of the respondents are highly interested in AVs and the level of interest in AVs increase with the increase in the level of automation as $5 \%$ of the respondents are interested in level- 0 automation, $8 \%$ are interested in level- $1 \mathrm{AVs}, 27 \%$ are interested in level-2 AVs, $34 \%$ are interested in level-3 AVs, and $26 \%$ are interested in level-4 AVs. Additionally, this survey shows that most Pakistanis believe that AVs are safe and will improve the level of safety as $75 \%$ of the respondents believe that AVs will improve traffic safety and reduce fatalities [89], which is consistent with Shafique et al. (2021) survey results [88] mentioned above. Additionally, EscandonBarbosa et al. (2021) survey investigated the impact of the risk perception on the willingness to pay AVs in Vietnam and Colombia. The results show that traffic safety is the main factor that affects the willingness to pay $\mathrm{AVs}$ followed by the financial risk [90].

\section{Benefits of AVs for developing countries}

The fatality rates in developing counties are much higher than in developed countries that the current trends indicate that road traffic injuries will become the fifth leading cause of death by 2030 , with the difference between highand low-income countries further magnified [84]. Statistic on fatal accidents in developing countries shows that the human factors are the main factor behind most of these accidents [91], which can be eliminated by AVs. Additionally, the deployment of AVs will be associated with a reduction in the vehicle ownership, accidents, emissions, and pollution. All these advantages will help people in developing countries to have healthier lives. Thus, AVs might be more critical for developing counties than developed countries as AVs will save the lives of many people. These benefits are associated with a high level of acceptance and interest in AVs [6] in developing countries than in developing countries as shown in all previous international surveys. However, AVs face multiple issues that might make it hard to test $\mathrm{AVs}$ in developing countries. These issues will be discussed in the next section.

\section{Challenges for AV deployment in developing countries}

\section{Road signs and marking}

AVs need highly visible curves, speed limits, and other signage in order to safely complete the tasks of driving, navigation, and parking [92-94]. However, the current marking and signing technique does not support AV navigation. For example, the two major issues facing AV navigation are the faded road marking and the non-standard road signs $[95,96]$. These two issues are commonly found in developing counties and will confuse AVs.

Road marking is essential for AV navigation and localization especially for camera-based localization techniques [93]. Previous filed studies on AVs show that missing road marking might cause unsafe navigation of AVs. However, in many developing countries there is a lack of the necessary marking as shown in the study by Huq et al. (2021) in India [97]. This study shows that many roads in India lack the stop lines, pedestrian crosswalks, lane marking, and edge marking. This lack of marking makes it challenging for AVs to operate safely on these roads.

The variation in the road signage, which is normal in the roads of developing countries, is the second challenge facing AVs, so coding is a main principle for sending information in a recognizable and standardized way. Standard colour, shape, font, line spacing, and luminance contrast are major factors that should be considered even for human drivers. However, the historical standards for coding have changed but outdated signs remain on the road network. Thus, this variety in the signage standards introduces new challenges for $\mathrm{AV}$ navigation. In general, there are many factors that impact the process of detection and recognition of the signs for AVs such as [21, 98]: 
Inconsistent signs: the lack of consistency in the application of signs, and sign location can be problematic and causes uncertainty on how the vehicle will react in these conditions.

Obscured signage: in many scenarios, signs might be Obscured partially or fully because of many factors such as other vehicles, vegetation, and the existing roadside infrastructure. This issue requires research in order to ensure the adequate detection of the signs in all conditions.

Varying illumination: many factors might affect the visibility of AVs such as the weather conditions, the low lighting conditions, and low sun angle. Additionally, the degraded retroreflective material will affect the visibility of AVs during night.

Lack of signage.

Developing countries suffer from all the previous signage issues. For example, the study by Huq et al. (2021) in India shows that most roads in India do not have stop signs, pedestrian crossing signs, lane merging signs, and lane split signs, and in many cases, traffic signals are not used at the intersections, which is confusing for AVs [97].

\section{Traffic management:}

AVs are expected to depend on accurate road mapping to complete their journey safely [99]. However, traffic incidents are stochastic events that change the road layout and AVs must be able to navigate safely in all cases. Additionally, roadway maintenance work is expected, which results in changing the road layout and the locations where the vehicles are expected to travel. As a result, depending on accurate mapping might not be enough as lane closures, and traffic incidences might add new risks [100]. While there are multiple websites that provide accurate information regarding traffic incidents in developed countries, such as waze. com in the UK, there is no such website in any developing country. Even more complex, these information from the websites only contains details reading the incidence cause and time without accurate information on the incidents' onsite conditions, which makes it hard for AVs to navigate safely even in developing countries [101]. As a result, this lack of real-time information might be problematic for the safe navigation of AVs where traffic incidents occurred in developing countries.

\section{Parking}

Research studies on the parking of AVs show that AVs can significantly reduce the number of the required parking lots, especially in the context of shared AVs as vehicles will be serving customers at different times, which reduces the number of required parking spots [15, 101]. Additionally, the autonomous valet parking system will allow vehicles to park closer to each other, and thus, the parking lots will be able to serve more vehicles. This provides new opportunities for both the users and the infrastructure provider as the user will not have to search for a space to park and increase the number of vehicles using the parking area doe parking owners. AVs have the potential to free up significant parking spaces and allow these spaces to be used in other activities, AV parking faces multiple issues in developing countries. Firstly, AV parking requires remote control of the vehicle by the parking operator which might expose the vehicle to cybersecurity threats also safeguards might be required if the vehicle does not respond. Secondly, AV parking will need an electronic payment method as no occupant will be in the vehicle. Thirdly, a major issue in the current parking lots is that most of them are privately owned and do not have a consistent marking system so the AVs will struggle in such an environment. Finally, the current parking lots do not support AV safe operations as most of the current parks are underground parks where the GPS signals are lost or weak, which causes confusion for AVs [102].

\section{Safer harbour area}

In the future, when AVs will operate on the roads, passengers will be able to participate in other activities. However, this introduces new issues and risks in case of vehicle malfunctioning or deterioration in the surrounding environment. This case might need some human interaction and ask the passengers to take control of the vehicle, but it is possible that the driver is not ready to take control of the vehicle so AVs will need a safe area to use until the driver takes control. As a result, the use of safe harbour areas is important for $\mathrm{AVs}$ to offer the vehicles a safe area in case the AV cannot operate safely in the current surrounding environment or in case of any malfunctioning [103]. In developed countries, the hard shoulder area is used along the road as the emergency refuge area (ERA) and can be used as a safe harbour area for AVs [100, 103]. In developed countries, the hard should is usually used for serving the running traffic, which makes it dangerous to be used as a safe harbour area for AVs.

\section{Traffic Heterogeneity}

As shown above, AVs have the potential to increase the lane capacity in developed countries without any infrastructure improvements. However, in developing countries, the lane capacity is greatly reduced by the heterogeneity of traffic as shown in Fig. 5-b. Non-motorized and motorized vehicles pass together through the same lane creating a haphazard situation and reducing the effective lane width. This heterogeneity of traffic will confuse AVs. 


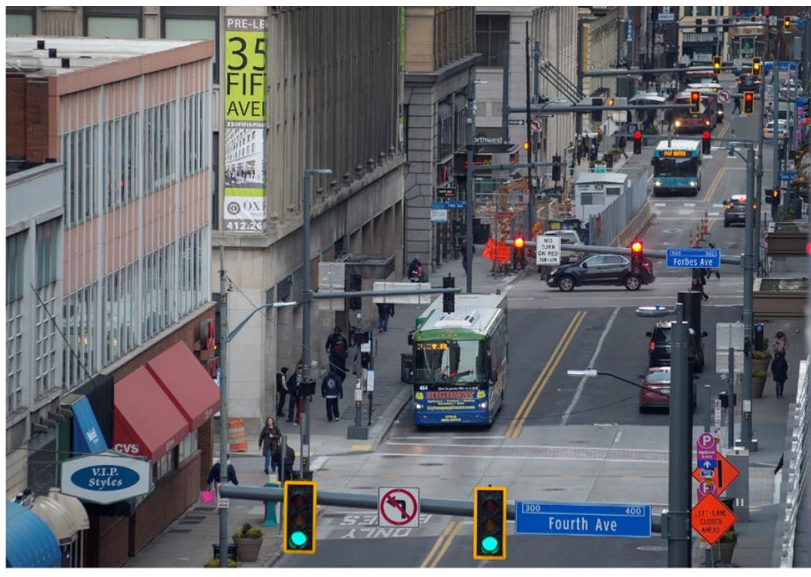

(a) Road with intersections (from the USA)

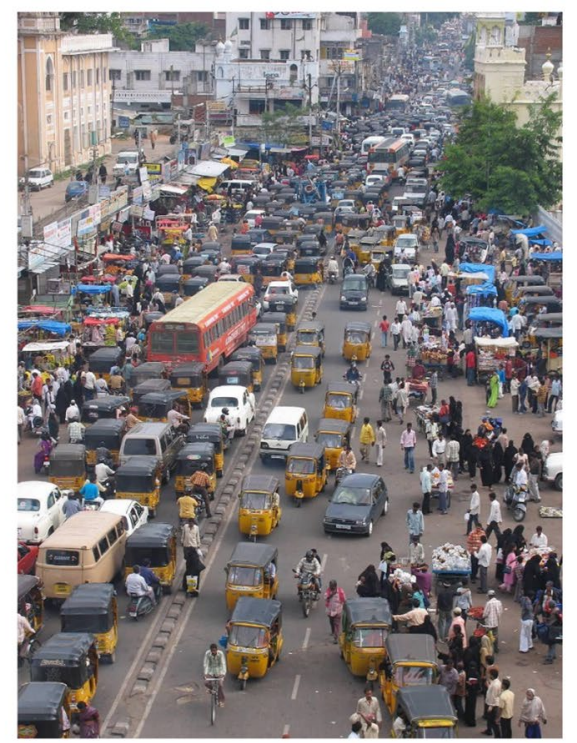

(b) Congested heterogeneous traffic conditions (from India) [104]

Fig. 5 Homogenous and heterogeneous traffic conditions [103]

\section{Summary of the challenges for the deployment of AVs}

The deployment of AVs in developing countries faces many issues such as the absolute lack of standardization in road infrastructure, poorly planned road network, lack of directional, informational and warning signals, and poor mapping of roads. All the currently existing algorithms which are being used and under research in the field of AV require a structured set of road infrastructure to work properly as in developed countries where everything is well structured. However, such a well-structured infrastructure network does not exist in most developing countries. Thus, it can be concluded that while people in developing countries are more optimistic towards AVs, the infrastructure challenges represent a major obstacle for the deployment of AVs.

\section{Impacts of the public perception on the adoption of AVs}

As mentioned before, public acceptance of AVs is considered a major factor for the success of AVs. Thus, this section briefly summarizes the impact of the public attitude and cultural dimensions on the adoption of AVs.

\section{Impact of previous experience with AV features (awareness)}

In order to investigate the impact of previous experience with AV features, Piao et al. (2016) conducted a survey and telephone interview in La Rochelle, France, after the end of a pilot AV project (autonomous shuttles) in the city. The results show that around $90 \%$ of the respondents are familiar with AV technology. Additionally, more than $65 \%$ of the respondents preferred AVs than human-driven vehicles. Additionally, $73 \%$ of the respondents with previous experience with AVs were optimistic about the adoption of AVs, while $55 \%$ of the respondents without previous experience with AV technology were optimistic about this new technology. Thus, previous experience with AVs has a significant influence on the public acceptance of AVs. A second approach to investigate the impact of previous experience with $\mathrm{AV}$ on the public attitude towards AVs is driving simulators [114]. Thus, Wintersberger, Riener and Frison (2016) used a driving simulator to understand the impact of previous experience with $\mathrm{AVs}$ on the public acceptance and questionnaires were conducted twice for every participant; one before and another after the trip to analyse the participants' attitude towards AVs. This study concluded that respondents with previous experience with AV are more optimistic about adopting this technology [115].

\section{Impact of the economic conditions on public acceptance of AVs}

In order to investigate the impact of the economic conditions on the public acceptance of AV, Bazilinskyy, Kyriakidis and De Winter (2015) conducted an international survey with 8862 respondents from 112 countries. Results of this study show that people from low-income countries are more optimistic towards AVs than people from medium- or highincome countries. The survey shows that 40,20 , and $23 \%$ of the respondent from low-, medium-, and high-income countries are optimistic about the adoption of AVs. Additionally, a large proportion of the respondent from high-income countries were concerned about the data transmission (privacy) and the software failure [86]. These results are consistent 
with the results of the other international surveys mentioned in Sect. (15).

\section{Willingness to pay:}

The willingness to pay is a key factor for the success of any new technology, especially in the initial state where the cost of the new technology is night hawker, previous surveys show that most respondents are not willing to pay more for AVs as summarized in Table 9.

\section{Precepting of AVs for different age groups:}

Although most studies arbitrarily assume that AVs have the potential to increase accessibility for aged individuals and consider this segment as the early adaptor of AVs [14, 36, $44,118,119]$, results of previous surveys that investigated the impact of the respondents' age on the public attitude towards AVs as summarized in Tables 10. Thus, the assumption that the aged will be of the early adaptors of AVs contradicts with the results of previous surveys and younger people might be the early adopters of AVs.

\section{Perception of males and females:}

Previous surveys show that males are always more optimistic towards AVs than females as summarized in Table 11.

\section{Summary of the impact of the demographics on the public attitude towards AVs}

Figure 6 summarizes the results of previous surveys mentioned in this study. (Table 12) The figure shows the minimum, maximum, and average percentages of the different

Table 9 summary of the selected studies that investigated the willingness to pay for AVs

\begin{tabular}{|c|c|}
\hline Survey & Results \\
\hline Schoettle and Sivak, (2014) [116] & $\begin{array}{l}60 \% \text { of the respondents are not willing to pay more for AV } \\
\text { technology, while } 10 \% \text { are willing to pay much more }\end{array}$ \\
\hline Kyriakidis, Happee and de Winter (2015) [79] & $\begin{array}{l}\text { AVs are more attracted to travellers who make long trips } \\
\text { and to people who live in countries with high accident } \\
\text { rates } \\
\text { Only } 5 \% \text { of the respondents are willing to pay more for AV } \\
\text { technology }\end{array}$ \\
\hline Cunningham, Ledger, and Regan (2018) [117] & $66 \%$ of the respondents are not willing to pay more for AVs \\
\hline
\end{tabular}

Table 10 Summary of the selected studies that investigated the perception of AVs for different age groups

\begin{tabular}{lc}
\hline Survey & Results \\
\hline Piao et al., (2016) [114] & $\begin{array}{c}56 \% \text { of respondents whose age is more than } 65 \text { would are optimistic towards AVs, } \\
\text { compared to } 62 \% \text { and } 61 \% \text { for people aged between } 18 \text { and } 34, \text { and } 35-64 \\
40 \% \text { of the respondents aged } 25-34 \text { years old prefer AVs, while only 12\% of the } \\
\text { Abraham et al., (2017) [120] }\end{array}$ \\
$\begin{array}{l}\text { respondents aged } 65-74 \text { years old consider making trips in AVs } \\
\text { people become discouraged about AVs with the increase in the number of years driving }\end{array}$ \\
\hline
\end{tabular}

Table 11 Summary of the selected studies that investigated the perception of AVs for males and females

\begin{tabular}{|c|c|}
\hline Survey & Results \\
\hline Schoettle and Sivak, (2014) [116] & Males are more positive towards AVs \\
\hline Schoettle and Sivak, (2015) [99] & $\begin{array}{l}40 \% \text { of the female respondents are concerned about fully Avs, while } 30 \% \text { of the male respondents are } \\
\text { concerned about fully Avs }\end{array}$ \\
\hline Piao et al., (2016) [114] & $\begin{array}{l}64 \% \text { of the male respondents agreed to make trips using Avs, while } 55 \% \text { of the female drivers agreed to } \\
\text { make trips in Avs }\end{array}$ \\
\hline Abraham et al., (2017) [120] & $\begin{array}{l}53 \% \text { of the male drivers trust Avs and agree to let the vehicle to take control, while } 40 \% \text { of the female } \\
\text { drivers trust Avs and would let the vehicle to take control }\end{array}$ \\
\hline Richardson and Davies (2018) [121] & $\begin{array}{l}\text { Females are more concerned about the risks of AVs } \\
60 \% \text { of the male respondents believe that AVs can improve the safety of traffic, while } 47 \% \text { of the female } \\
\text { respondents agree that AVs improve traffic safety }\end{array}$ \\
\hline
\end{tabular}




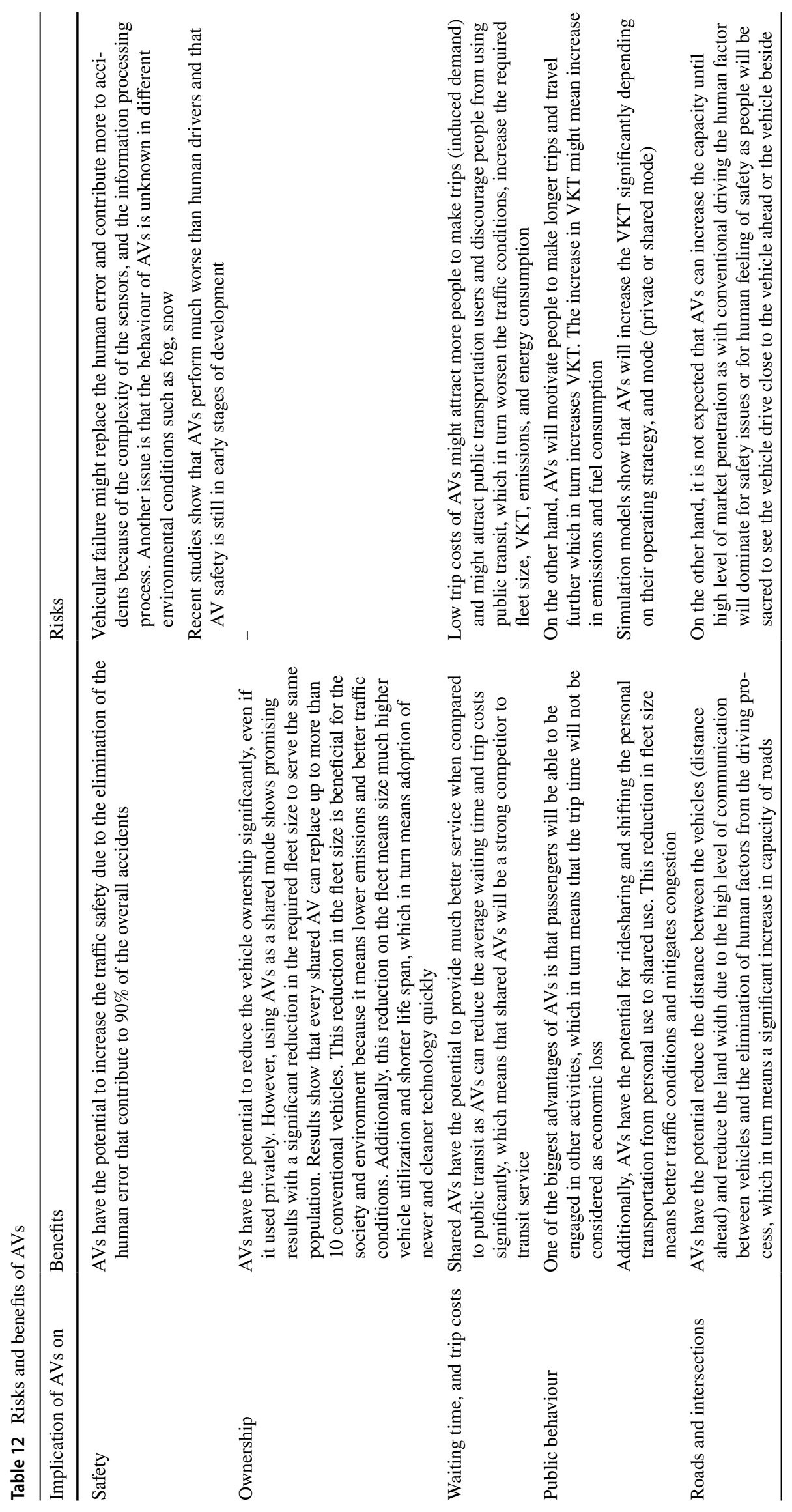




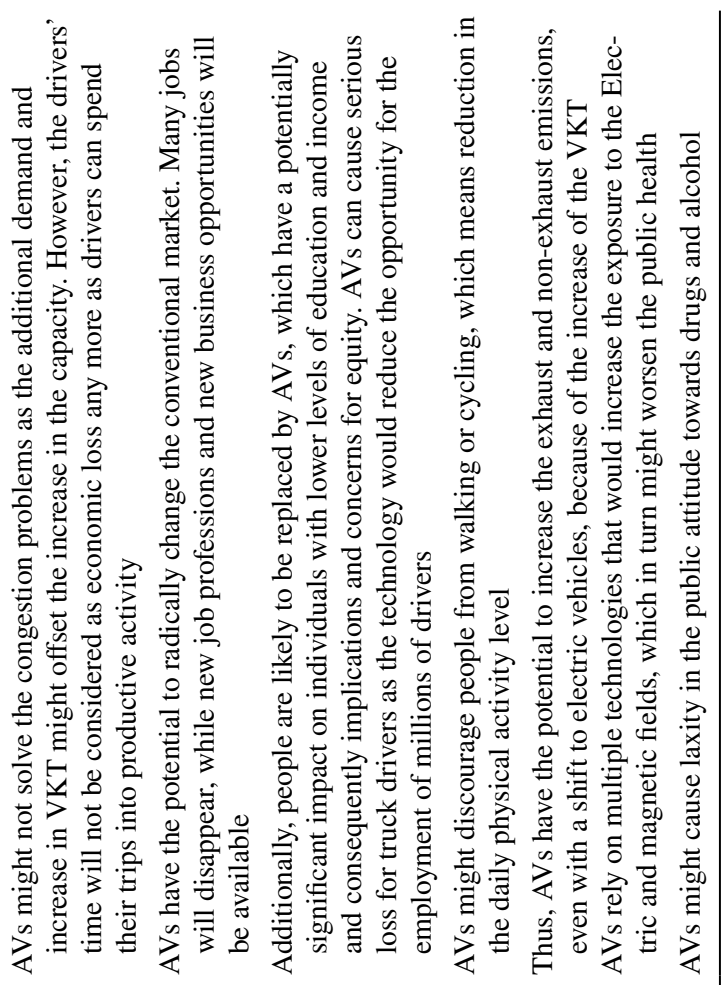

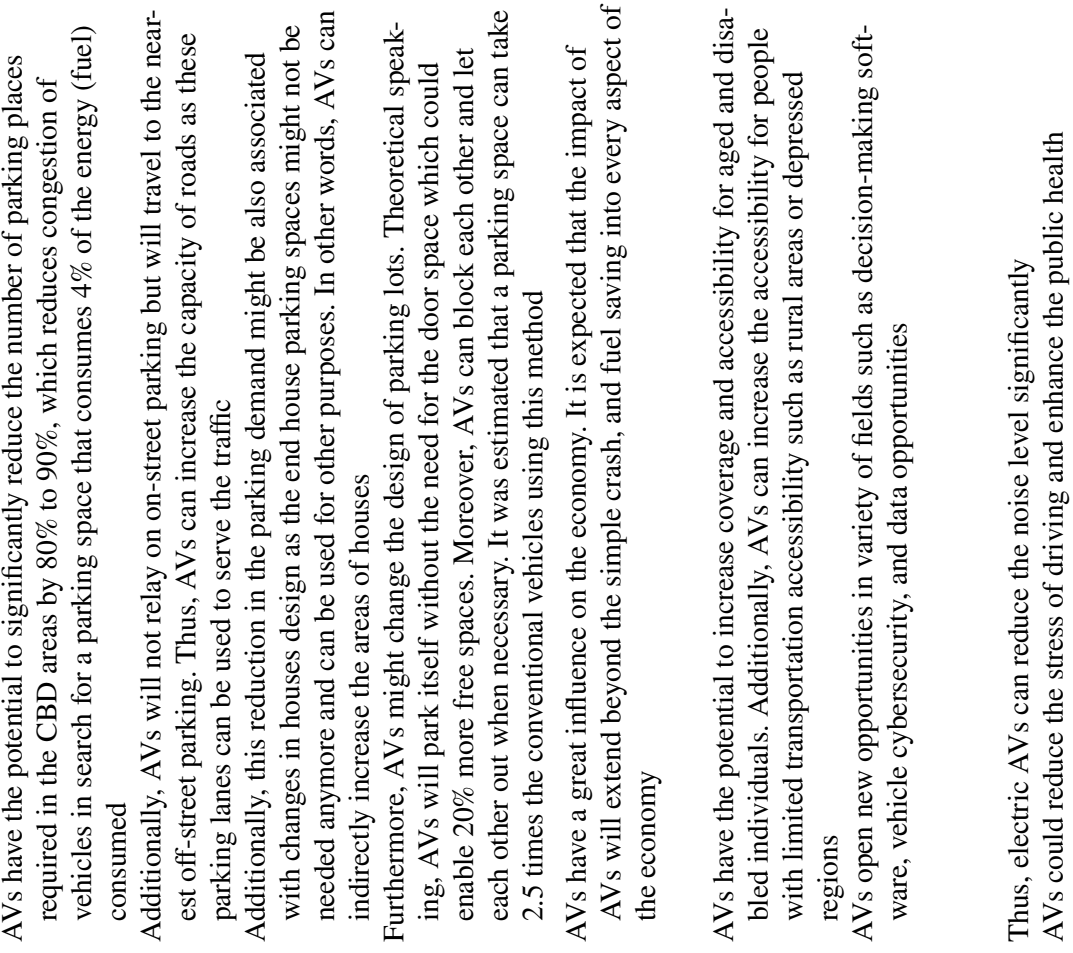

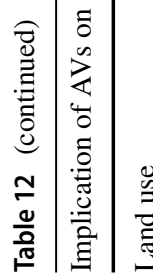

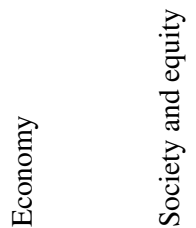

壱 
Fig. 6 Summary of the of the public perception of $\mathrm{AVs}$

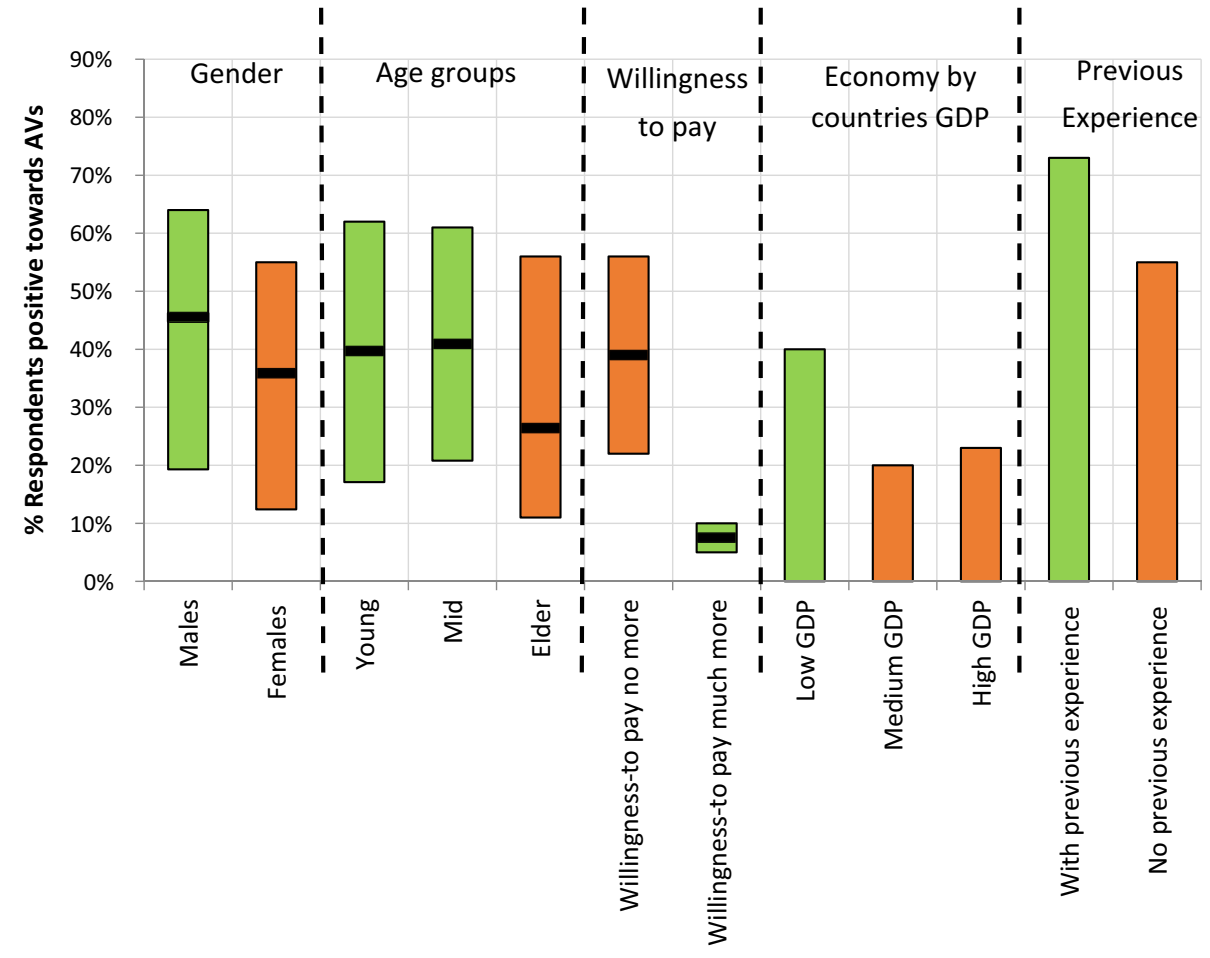

Positive

Negative

Average value demographic studies in this section. The figure shows that females are more concerned about AVs than males. Additionally, younger people are more optimistic towards AVs than older people. Furthermore, most people are not willing to pay more for the new technology. Moreover, people from high-income countries are more concerned about the security and privacy of AVs than people from low-income countries. Finally, previous experience with AVs increases the level of acceptance of AVs and attracts people towards AV technology.

\section{Implications of AVs on traffic safety}

Safety of AVs is essential to their success in the market and society [122]. The main advantage of AVs is their quick response when compared to the human driver [123]. Moreover, AVs are programmed so that they can obey the rules of the roads, cannot be distracted by the phone [124]. For example, Papadoulis et al. (2019) investigated the impact of different levels of penetration of AVs on the safety of traffic using Vissim simulation models and evaluated the safety of every penetration rate using the Surrogate Safety Assessment Model (SSAM). Results of this study show that AVs can significantly improve traffic safety and the level of safety increase with the increase in the level of penetration of AVs. Specifically, the results show that AVs reduce traffic conflicts by up to $47,80,92$ and $94 \%$ with $25,50,75$ and $100 \%$ AV penetration rates, respectively [125]. Similarly, Ye, and Yamamoto (2019) investigated the impact of AVs with different penetration rates on the safety of traffic using a simulation model. The impact of the different penetration levels of AVs on the safety was assessed based on the frequency of dangerous situations and the value of time to collision in the mixed traffic flow under different AV penetration rates. Additionally, the acceleration rate and speed difference distribution of the traffic were used to understand the evolution of the network dynamics under different AV penetration rates. The results of this study show that traffic safety can be significantly improved with the increase of AV penetration rate. Additionally, the simulation models show that the portion of smooth driving increases with the increase in AV penetration [126]. Aside from simulation models, AVs are usually programmed to make decisions using machine learning and artificial intelligence (AI) techniques. The use of AI to improve the safety and make decisions in AVs has achieved some progress; however, this progress is not significant because of the complexity of the vehicle in terms of electrical and mechanical components and the variety of external conditions such as weather, road conditions, topography and traffic pattern [122, 123]. Additionally, an important factor that has contributed to recently reported crashes in AVs is the transition from the conventional mode to the AVs [with its various levels]. Another 
behavioural aspect that is indirectly related to safety is the normal eye contact-feedback-proceed two-way communication between drivers in adjacent cars in conflicting situations; a behavioural component that is either absent in full $\mathrm{AV}$ penetration; or more confusing in conventional vs AV mixed conditions [123]. These challenges forced Waymo CEO John Krafcik in November 2018 to state that he does not believe that $\mathrm{AV}$ technology will ever be able to operate in all possible conditions without some human interaction $[127,128]$. Consequently, solving the safety issue requires a multidisciplinary effort between science, technology and manufacturing. Typically, an AV contains more than 50 processors and accelerators that run millions of codes to support the vision of the vehicle in order to make the appropriate decision. Additionally, the behaviour of AVs is unpredictable in all scenarios unless it is trained for these problems in real work; however, there are hundreds of scenarios that the vehicle might face [122]. Therefore, it is fair to state that the level of development and data to support the safety of autonomy is still in the early stages [129]. The data collected between 2014 and 2017 by the research team at the University of Illinois for $114 \mathrm{AVs}$ that travelled almost 1.1 million kilometres showed that the human drivers are 4000 times less likely to have an accident [122]. One of the proposed solution is the approach followed by Tesla as in 2016 when Tesla announced that their vehicles are able to travel autonomously; however, this feature will operate in the shadow mode. In the shadow mode, the vehicle can make decisions but these decisions are not executed but the human driver's decisions are the decisions executed instead [130]. This approach helps in gathering information about the decisions of the vehicles and compares these decisions with the human river actions in order to train the vehicle to take the actions that mimic the human driver's actions. Additionally, this approach helps the manufacturer of $\mathrm{AVs}$ to understand how AVs learn and improve over time.

\section{Conclusions}

It has been three decades since Mercedes-Benz and Bundeswehr University in Munich invented the first AV in the world. Over the last decade, AV technology has seen rapid improvement as both research and industry are putting significant efforts into the development of AVs. This paper reviews the current state of the art of AV implications on public behaviour, land use, economy, society and environment, and public health. While AVs hold many benefits, they
Strengths

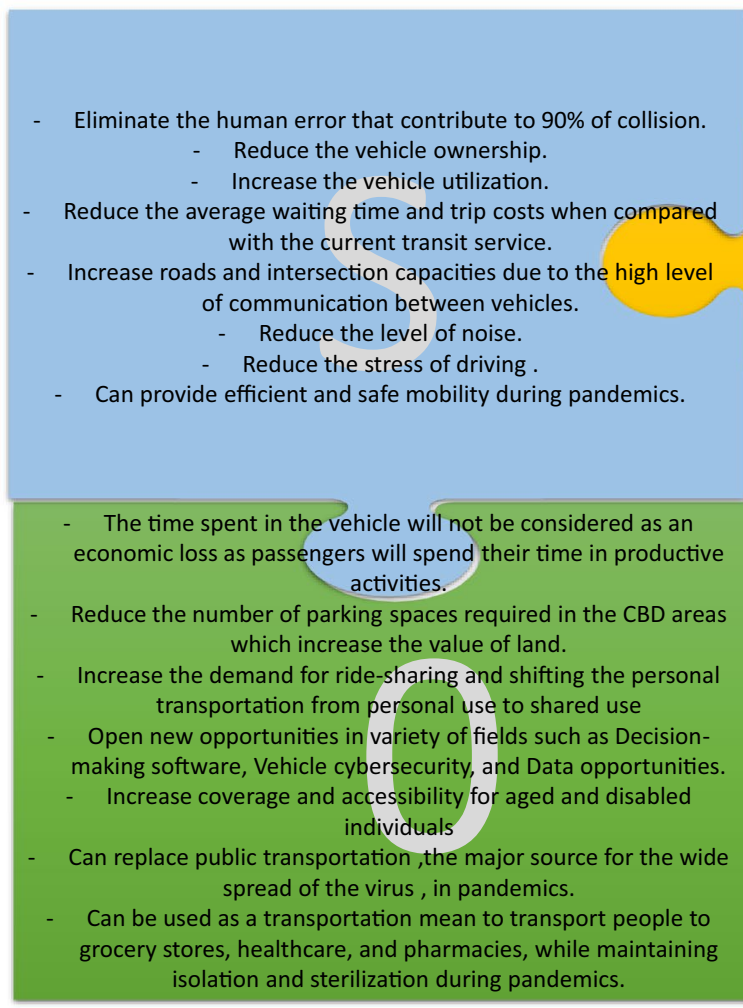

Opportunities

\section{Weaknesses}

Vehicular failure might contribute more to accidents and might replace the human error.

No practical way for testing autonomous vehicle safety prior to the widespread of AVs

No consensus on how safe autonomous vehicles should be.

Regulations follow the development of AVs instead of taking the lead.

Businesses companies that are unable to adapt to this change will suffer significant loss.

Reduce the daily physical activity, increase the exposure to the electromagnetic fields.

Increase the non-exhaust emissions, even with a shift to electric vehicles.

cause laxity in the public attitude towards substance abuse.

High level of fear of AVs as people might not accept the idea of leaving their lives in the hands of machines.

Increase the VKT, which increase the emissions and worsen the traffic condition.

Motivate people to make additional trips and travel further. Attract public transportation users.

Many jobs will disappear, while new job and new business opportunities will be available.

New risks will emerge such as the cyber-attacks.

People are likely to be replaced by AVs, which have a potentially

significant impact on individuals with lower levels of education

and income and consequently implications and concerns for equity.

Reduce the opportunity for the employment of millions of drivers

\section{Threats}

Fig. 7 SWOT analysis for AV technology 
also hold many risks as summarized in Table 9 and Fig. 7 which summarizes the strengths, weaknesses, opportunities, and threats (SWOT analysis) of AV technology mentioned in this study. This paper shed the light on many strengths and weaknesses of $\mathrm{AVs}$ and the intertwined relationships between them as follows:

- AVs have the potential to reduce vehicle ownership. The pilot studies in Singapore emphasize this ownership reduction, as results show $15 \%$ reduction in the vehicle ownership due to the spread of AVs in 2018 [24].

- Shared AVs have the potential to provide excellent service to the public as AVs can significantly reduce the average waiting time and trip costs, but this might encourage people to make additional trips (induced demand) and might attract transit users, which in turn increases the VKT, emissions, and energy used. One positive sign is that most of the cities testing AVs are testing autonomous shuttles or autonomous buses with the aim of solving the first mile and last mile problem and increase the reliance on public transit.

- AVs allow passengers to be engaged in other activities, which means that the trip time will not be considered as an economic loss. On the other hand, this will motivate people to make longer trips and travel further which in turn increases VKT, emissions, and energy consumed.

- AVs have the potential to significantly reduce the parking demand by 80 to $90 \%$ as reported in the previous studies [16, 19,39], which in turn reduces congestion of vehicles searching for a parking space. Additionally, the freed-up parking spaces can be used for other purposes. For example, using the parking areas in the real estate industry can increase the value of land use. Additionally, this reduction in the parking demand might be also associated with changes in house design as the end house parking spaces might not be needed anymore and can be used for other purposes.

- AVs have the potential to reduce emissions and energy due to the platooning effect, smooth start and stops, reduction in the number of engine starts because of the reduction in required fleet size. Additionally, AVs open the way towards the application of the system optimal traffic assignment.

- AVs have a great influence on the economy. It is expected that the impact of AVs will extend beyond the simple crash, and fuel saving into every aspect of the economy. It is expected that AVs will revolutionize the economy in ways that have not been seen before.

- AVs open new opportunities in variety of fields such as decision-making software, vehicle cybersecurity, and data opportunities. On the other hand, people are likely to be replaced by AVs, which have a potentially significant impact on individuals with lower levels of education and consequently concerns for equity. AVs can cause a serious loss for truck drivers as the technology would reduce the opportunity for the employment of millions of drivers.

- $\mathrm{AVs}$ have the potential to increase coverage and accessibility for aged, disabled individuals, and people with limited transportation such as people in rural areas.

- Implications of AVs on public health could vary depending on many factors such as the type of use or ownership, automation level, and the type of engine such as internal combustion, and hybrid engines. While AVs might increase some risks such as pollution, sedentarism, and exposure to the electric and magnetic fields, AVs might provide some benefits such as the reduction in the stress of driving, and the reduction in the noise level. Public health can benefit from the proper regulations if these regulations are implemented before the introduction of $\mathrm{AVs}$ in the market.

- In pandemics, AVs can be used for food and medical supplies delivery and sanitize streets. Additionally, AVs can be used as a transportation mean to transport people to grocery stores, healthcare, and pharmacies, while maintaining isolation and sterilization.

- The fatality rates in developing counties are much higher than in developed countries that the current trends indicate that road traffic injuries will become the fifth leading cause of death by 2030 , with the difference between high- and low-income countries further magnified. The main source of accidents in developing countries is the human drivers which can be eliminated by AVs. Thus, the value of AVs in developing counties is higher than the value of AVs in developed countries as AVs will save more lives. This high value of AVs is associated with a high level of acceptance and interest in AVs in developing countries than in developing countries as shown in all previous international surveys. However, AVs face multiple issues and challenges that might make it hard to deploy or test AVs in developing countries soon. These challenges include but not limited to: the poor signage and marking standards, the lack of most basic marking and signage, the poor parking design that does not support AV navigation in terms of marking or signage consistency and the required navigation technology in case of underground parking, and traffic Heterogeneity that might confuse AVs.

- Although residents of developing counties are more optimistic towards AVs than residents of developed countries, the infrastructure and behavioural challenges will force developing countries to delay the adoption of AVs.

- The broader implications of AVs will be dependent on how the technology is adopted in various transportation systems. Regulatory action will be a significant determinant of how AVs could affect our lives, as well as how 
AVs influence the public behaviour, land use, economy, public health, environment, and society.

\section{Direction for future research}

Although there is a large number of studies that focuses on $\mathrm{AVs}$, there are multiple research gap that requires further studies and analysis as follows:

Induced demand: AVs will allow people to be engaged in other activities during their trips, which will motivate people to create additional trips and travel further. Thus, the assumption that the travel demand is unchangeable, as stated in all simulation studies, is not true as AVs will be less expensive (as a shared public mode of transportation) and thereof induced demand is inevitable; the magnitude of which is yet to be succinctly and evidently studied/estimated by transportation planners. This gap is more important to be addressed now than ever as the anticipated travel demand implications might offset some of the perceived benefits of AVs as the added trips generated besides with the VKT increase might offset the benefits of AVs and cause a high level of congestion and emissions, which means that AVs might represent a huge risk on the network and the public health. Thus, further research studies are required to understand the impact of AVs on the travelling behaviour and estimate the expected increase in the trips generated because of the attractiveness of AVs.

Public behaviour: Further studies are required to understand the change in public choices. For example, is it realistic that people might prefer to live further from work and spend their trip sleeping? If so, how far or what is the increase in the trip length and total VKT? What is the impact on the origin-destination matrices? For example, what is the impact on the distribution of people in urban and rural areas?

Elder and disabled accessibility: AVs are expected to increase the accessibility for the elders and disabled. While the disabled are considered to be one of the early adaptors of the AVs, no study surveyed this group to understand their acceptance of the AVs. As a result, future studies are required for this group instead of making assumptions. Similarly, the elders are considered of the early adaptors of the $\mathrm{AVs}$ as $\mathrm{AVs}$ will increase their accessibility. However, previous surveys show that the elder group is the most pessimistic group towards AVs $[114,120,121]$ which contradicts the theories that the elder will benefit more from the AVs. In other words, it is noteworthy that, although accessibility to the elderly and disabled was among the key drivers/benefits of AV selling point, little to no research focused on the disabled group to understand their acceptance of AVs. Addi- tionally, although the elders were thought to be among the early adaptors of AVs to improve their accessibility; results showed that younger people are more interested in AVs which questions the hypothesis that the elder would benefit more from AVs.

Implications of AVs on developing countries: Further studies are required to understand and quantify the implications of AVs on the land use, public behaviour, emissions, and roads and intersection capacity of developing countries. To the moment, there is no single simulation model developed in any developing country to understand how AVs will affect people of developing countries. Additionally, further research studies are required to propose solutions for the issues and challenges facing AV deployment in developing countries.

Authors' contributions KO took part in literature search and review, research methodology, data preparation, data analysis, and manuscript writing and reviewing.

\section{Declarations}

Conflict of interest The authors declare that they have no competing interests.

\section{References}

1. The Milwaukee Sentinel (1926) Phantom Auto' will tour city. 8 December

2. The Victoria Advocate (1957) Power companies build for your new electric living. 24 Mars

3. Davidson P, Spinoulas A (2015) Autonomous Vehicles - What Could This Mean for the Future Of Transport? AITPM 2015 National Conference. Sydney

4. Berrada J, Leurent F (2017) Modeling Transportation Systems involving Autonomous Vehicles: A State of the Art. Transportation Research Procedia. In: 20th EURO Working Group on Transportation Meeting, EWGT 2017, Budapest, Hungary

5. Greenblatt JB, Shaheen S (2015) Automated vehicles, on-demand mobility, and environmental impacts. Curr Susta Renew Energy Rep 2:74-81. https://doi.org/10.1007/s40518-015-0038-5

6. Othman K (2021) Public acceptance and perception of autonomous vehicles: a comprehensive review. AI and Ethics. https:// doi.org/10.1007/s43681-021-00041-8

7. Mallozzi P, Pelliccione P, Knauss A, Berger C, Mohammadiha N (2019) Autonomous Vehicles: State of the Art, Future Trends, and Challenges. In: Automotive Systems and Software Engineering. Springer. https://doi.org/10.1007/978-3-030-12157-0_16

8. Hartmans A (2016) How Google's self-driving car project rose from a crazy idea to a top contender in the race toward a driverless future. https://www.businessinsider.com/google-driverlesscar-history-photos-2016-10

9. O'Kane S (2019) Uber debuts a new self-driving car with more fail-safes. https://www.theverge.com/2019/6/12/18662626/ubervolvo-self-driving-car-safety-autonomous-factory-level

10. Staff M (2019) Apple's vehicle project, focused on building an autonomous driving system. https://www.macrumors.com/round up/apple-car/\#release_date 
11. Taylo T (2018) Top 8 self-driving startups to watch in 2018 and 2019. http://techgenix.com/self-driving-startups/

12. National Conference of State Legislatures (2020) Autonomous Vehicles I Self-Driving Vehicles Enacted Legislation. https:// www.ncsl.org/research/transportation/autonomous-vehicles-selfdriving-vehicles-enacted-legislation.aspx

13. Laukkonen J (2020) Are Self-Driving Cars Legal in Your State? https://www.lifewire.com/are-self-driving-cars-legal-4587765

14. Securing America's Future Energy (SAFE) (2018) America's Workforce and the Self-Driving Future: Realizing Productivity Gains and Spurring Economic Growth

15. KPMG (2015) Connected and Autonomous Vehicles - The UK Economic Opportunity

16. International Transport Forum. Urban Mobility System Upgrade - How shared self-driving cars could change city traffic

17. Burns L, Jordan W, Scarborough B (2012) Transforming Personal Mobility. The Earth Institute - Columbia University

18. Fagnant D, Kockelman K (2014) The travel and environmental implication of shared autonomous vehicles using agent-based model scenarios. Transport ResPart C: Emerg Technol. 40:1-13. https://doi.org/10.1016/j.trc.2013.12.001

19. Zhang W, Guhathakurta S, Fang J, Zhang G (2015) Exploring the impact of shared autonomous vehicles on urban parking demand: an agent-based simulation approach. Sustain Cities Soc. https:// doi.org/10.1016/j.scs.2015.07.006

20. Bischoff J, Maciejewski M (2016) Simulation of city-wide replacement of private cars with autonomous taxis in Berlin. Procedia Comp Sci. 83:237-244

21. Abdelgawad H, Othman K (2020) Multifaceted Synthesis of Autonomous Vehicles' Emerging Landscape. In: Connected and Autonomous Vehicles in Smart Cities, $1^{\text {st }}$ edn. CRCTaylor\&Francis, Boca Raton, Florida, USA https://doi.org/10. 1201/9780429329401-3

22. Moreno A, Michalski A, Llorca C, Moeckel R (2018) Shared autonomous vehicles effect on vehicle-km traveled and average trip duration. J Adv Transp 2018:1-10. https://doi.org/10.1155/ 2018/8969353

23. Zhang W, Guhathakurta S, Khalil E (2018) The impact of private autonomous vehicles on vehicle ownership and unoccupied VMT. Transport Res Part C: Emerg Technol. https://doi.org/10. 1016/j.trc.2018.03.005

24. Apur (2018) Impacts and potential benefits of autonomous vehicles

25. Fan Y, Guthrie A, Levinson D (2016) Waiting time perceptions at transit stops and stations: effects of basic amenities, gender, and security. Transport Res Part A: Policy and Pract. 88:251-264. https://doi.org/10.1016/j.tra.2016.04.012

26. Wardman M (2004) Public transport values of time. Transp Policy 11(4):363-377

27. Horowitz AJ (1981) Subjective value of time in bus transit travel. Transportation 10:149-164. https://doi.org/10.1007/BF00165263

28. Abrantes P, Wardman M (2011) Meta-analysis of UK values of travel time: an update. Transp Res Part A: Policy and Pract 45:1-17. https://doi.org/10.1016/j.tra.2010.08.003

29. Metro Magazine (2014) U.S. commuters wait approximately 40 mins. a day for public transit. https://www.metro-magazine.com/ accessibility/news/292870/u-s-commuters-wait-approximately40-mins-a-day-for-public-transit

30. Global news wire (2014) SURVEY: U.S. Commuters Wait Approximately 40 Minutes per Day for Public Transit, Costing Them 150 Hours per Year. https://www.globenewswire.com/ news-release/2014/12/09/1126354/0/en/SURVEY-U-S-Commu ters-Wait-Approximately-40-Minutes-per-Day-for-Public-Trans it-Costing-Them-150-Hours-per-Year.html

31. Lamont J (2019) Moovit's 2019 transit report shows long commutes in Canadian cities. Mobilesyrup. https://mobilesyrup. com/2020/01/15/moovit-2019-transit-report-canadian-citiescommute-statistics/

32. Azevedo L et al (2016) Micro simulation of demand and supply of autonomous mobility on demand. Transport Res Rec J Transport Res Board. https://doi.org/10.3141/2564-03

33. Hörl S, Erath A, Axhausen K (2016) Simulation of autonomous taxis in a multi-modal traffic scenario with dynamic demand

34. The Polis Traffic Efficiency and Mobility Working Group (2018) Road Vehicle Automation and Cities and Regions

35. Barth M, Boriboonsomsin K, Wu G (2014) Vehicle Automation and Its Potential Impacts on Energy and Emissions. https:// doi.org/10.1007/978-3-319-05990-7_10

36. Miller S, Heard BR (2016) The environmental impact of autonomous vehicles depends on adoption patterns. Environ Sci Technol 50(12):6119-6121

37. Metz D (2018) Developing policy for urban autonomous vehicles: impact on congestion. Urban Science. 2(2):33

38. Clements LM, Kockelman KM (2017) Economic effects of automated vehicles. Transp Res Rec 2606(1):106-114

39. Zhang W, Guhathakurta S (2017) Parking spaces in the age of shared autonomous vehicles: how much parking will we need and where? Transp Res Rec 2651(1):80-91

40. Friedrich B (2016) The Effect of Autonomous Vehicles on Traffic. Autonomous Driving: 317-334

41. Wagner P (2016) Traffic Control and Traffic Management in a Transportation System with Autonomous Vehicles. Autonomous Driving: 301-316

42. Compass Transportation and Technology (2018) The Economic and Social Value of Autonomous Vehicles: Implications from Past Network-Scale Investments. prepared for: Securing America's Future Energy (SAFE)

43. Catapult transport systems (2017) Future Proofing Infrastructure for Connected and Automated Vehicles. Technical Report

44. Brown A, Gonder J, Repac B (2014) An Analysis of Possible Energy Impacts of Automated Vehicle. https://doi.org/10.1007/ 978-3-319-05990-7_13

45. United states Environmental protection agency (2020) Sources of Greenhouse Gas Emissions" https://www.epa.gov/ghgem issions/sources-greenhouse-gas-emissions

46. Europe Environment Agency (2019) Greenhouse gas emissions from transport in Europe

47. Development Engineering and Infrastructure Planning (2019) Sustainable Transportation. https://www.vaughan.ca/projects/ projects_and_studies/sustainable_transportation/Pages/default. aspx

48. Clark B Y, Larco N, Mann R F (2017) The Impacts of Autonomous Vehicles and E-Commerce on Local Government Budgeting and Finance

49. Gittleman M, Monaco K (2020) Truck-driving jobs: are they headed for rapid elimination? ILR Rev 73(1):3-24. https://doi. org/10.1177/0019793919858079

50. Dons E et al (2015) Physical activity through sustainable transport approaches (PASTA): protocol for a multi-centre, longitudinal study. BMC Public Health 15(1):1126

51. Rojas-Rueda D et al (2011) The health risks and benefits of cycling in urban environments compared with car use: health impact assessment study. BMJ. 343:d4521

52. Rojas-Rueda D et al (2012) Replacing car trips by increasing bike and public transport in the greater Barcelona metropolitan area: a health impact assessment study. Environ Int 49:100-109

53. Soteropoulos A, Berger M, Ciari F (2019) Impacts of automated vehicles on travel behaviour and land use: an international review of modelling studies. Transp Rev 39:29-49

54. Rojas-Rueda D et al (2013) Health impact assessment of increasing public transport and cycling use in Barcelona: a 
morbidity and burden of disease approach. Appendix Prev Med 57(5):573-579

55. Health Effects Inst. (2018) State of Global Air/2018. A special report on global exposure to air pollution and its disease burden. Rep., Health Effects Inst., Boston. https://www.stateofglo balair.org/sites/default/files/soga-2018-report.pdf

56. Amato $\mathrm{F}$ et al (2014) Urban air quality: the challenge of traffic non-exhaust emissions. J Hazard Mater 275:31-36

57. Rojas-Rueda D, Turner MC (2016) Commentary: diesel, cars, and public health. Epidemiology 27(2):159-162

58. Anenberg S et al. (2019) A global snapshot of the air pollution-related health impacts of transportation sector emissions in 2010 and 2015. Rep., Int. Counc. Clean Transp. (ICCT), Washington, DC. https://theicct.org/sites/default/files/publi cations/Global_health_impacts_transport_emissions_20102015_20190226.pdf

59. Timmers V, Achten P (2016) Non-exhaust PM emissions from electric vehicles. Atmos Environ 134:10-17

60. Rojas-Rueda D, Nieuwenhuijsen MJ, Khreis H, Frumkin H (2020) Autonomous Vehicles and Public Health. Annu Rev Public Health 41(1):329-345. https://doi.org/10.1146/annur ev-publhealth-040119-094035

61. Basner M, McGuire S (2018) WHO environmental noise guidelines for the European Region: a systematic review on environmental noise and effects on sleep. Int J Environ Res Public Health 15(3):E519

62. Brown AL, Van Kamp I (2017) WHO environmental noise guidelines for the European Region: a systematic review of transport noise interventions and their impacts on health. Int J Environ Res Public Health 14:E873

63. Brown AL (2015) Effects of road traffic noise on health: from burden of disease to effectiveness of interventions. Procedia Environ Sci 30:3-9

64. WHO (World Health Organ.) Eur.Cent.Environ.Health (2011) Burden of disease from environmental noise: quantification of healthy life years lost in Europe. Rep.,WHO Reg. Off. Eur., Bonn, Ger. http://www.euro. who.int/__data/assets/pdf_ file/0008/136466/e94888.pdf

65. Verheijen E, Jabben J (2010) Effect of electric cars on traffic noise and safety.RIVM Lett. Rep. 680300009/2010, Natl. Inst. Public Health Environ. (RIVM), Bilthoven, Neth.

66. Natl. Cancer Inst. (2019) Electromagnetic fields and cancer. Fact Sheet, Natl. Cancer Inst., Bethesda, MD. https://www. cancer.gov/about-cancer/causes-prevention/risk/radiation/elect romagnetic-fieldsfact- sheet

67. Natl. Toxicol. Progr. (2018) The toxicology and carcinogenesis studies in Hsd:Sprague Dawley SD rats exposed to whole-body radio frequency radiation at a frequency $(900$ mhz) and modulations (GSM and CDMA) used by cell phones. NTP Tech. Rep. 595, Natl. Toxicol. Progr. (NTP), Research Triangle Park, NC. https://ntp.niehs.nih.gov/ntp/ htdocs/lt_rpts/tr595_508.pdf?utm_source $=$ direct\&utm medium $=$ prod\&utm_campaign $=$ ntpgolinks\&utm_term $=\operatorname{tr} 595$

68. NHTSA (Natl. Highw. Traffic Saf. Adm.) (2019) Drugimpaired driving. NHTSA. https://www.nhtsa.gov/risky-drivi ng/drug-impaired-driving

69. Off. Surg. Gen (2016) Facing addiction in America: the Surgeon General's report on alcohol, drugs, and health. Rep., US Dep. Health Hum. Serv., Washington, DC. https://addiction. surgeongeneral.gov/sites/default/files/surgeon-generals-report. pdf

70. Natl. Transp. Comm. (2018) Changing driving laws to support automated vehicles. Policy Pap., Natl. Transp. Comm., Melbourne. https://www.ntc.gov.au/sites/default/files/assets/files/ NTC\% 20Policy\% 20Paper\%20-\%20Changing\%20driving\% 20laws $\% 20$ to\%20support $\% 20$ automated\%20vehicles.pdf
71. Antoun M, Edwards KM, Sweeting J, Ding D (2017) The acute physiological stress response to driving: a systematic review. PLoS One 12(10): 0185517

72. Mariotti A (2015) The effects of chronic stress on health new insights into the molecular mechanisms of brain body communication. Futur Sci OA. 1(3):FS023

73. Crowe S, Argo A I, Aurora C, Pony A (2020) Uber halt selfdriving tests due to COVID-19. The robot report.. https://www. therobotreport.com/argo-ai-aurora-cruise-pony-ai-uber-auton omous-vehicles-covid/

74. Tchir J (2020) Could physical distancing reignite our excitement for autonomous driving? The globe and mail. https:// www.theglobeandmail.com/drive/mobility/article-couldsocial-distancing-reignite-our-excitement-for-autonomousdriving/

75. Grosbard E (2020) Autonomous vehicles could be crucial in responding to future pandemics. The robot report. https://www. thero botre port.com/auton omous -vehicles-vital -role-solvi ngfuture-pande mics/

76. Demaitre E (2020) COVID-19 pandemic prompts more robot usage worldwide. The robot report. https ://www.thero botre port. com/covid -19-pande mic-promp ts-more-robot -usage -world wide/

77. Ford T (2020) Autonomous shuttles help transport COVID19 tests at Mayo Clinic in Florida. Mayo Clinic. https://newsn etwork.mayoclinic.org/discussion/autonomous-shuttles-helptransport-covid-19-tests-at-mayo-clinic-in-jacksonville/

78. Goscé L, Johansson A (2018) Analysing the link between public transport use and airborne transmission: mobility and contagion in the London underground. Environ Health 17:84. https://doi. org/10.1186/s12940-018-0427-5

79. Kyriakidis M, Happee R, de Winter JCF (2015) Public opinion on automated driving: results of an international questionnaire among 5000 respondents, transportation research part $\mathrm{f}$ : traffic psychology and behaviour, volume 32, 2015. ISSN 127 140:1369-8478. https://doi.org/10.1016/j.trf.2015.04.014

80. Hong J (2013) Considering privacy issues in the context of Google Glass. Commun ACM 56:10-11. https://doi.org/10.1145/ 2524713.2524717

81. Segall JE (2010) Google street view: walking the line of privacyintrusion upon seclusion and publicity given to private facts in the digital age. Pittsburgh J Technol Law \& Policy. https://doi. org/10.5195/tlp.2010.51

82. Debatin B, Lovejoy JP, Horn AK, Hughes BN (2009) Facebook and online privacy: attitudes, behaviors, and unintended consequences. J Comput-Mediat Commun 15:83-108. https://doi.org/ 10.1111/j.1083-6101.2009.01494.x

83. Weinstein M (2013) Facebook Privacy Issues Is Privacy Dead. From http://www.huffingtonpost.com/tag/facebookpr ivacy-issues/

84. World Health Organization (2013) Global status report on road safety 2013: supporting a decade of action. Luxembourg

85. Maslow AH (1943) A theory of human motivation. Psychol Rev 50:370-396

86. Bazilinskyy P, Kyriakidis M, de Winter J (2015) An international crowdsourcing study into peoples statements on fully automated driving. Procedia Manufact. https://doi.org/10.1016/j.promfg. 2015.07.540

87. Moody J, Bailey N, Zhao J (2019) Public perceptions of autonomous vehicle safety: an international comparison. Saf Sci. https:// doi.org/10.1016/j.ssci.2019.07.022

88. Shafique M A, Afzal M S, Ahmed A (2021) Public Perception regarding Autonomous Vehicles in Developing Countries: A Case study of Pakistan. Pakistan Journal of Engineering and Applied Sciences, University of Engineering and Technology Lahore. Vol. 28 January, 2021 (p. 1-6) 
89. Sanaullah I, Hussain A, Chaudhry A, Case K, Enoch M (2017) Autonomous Vehicles in Developing Countries: A Case Study on User's View Point in Pakistan. In: Stanton N., Landry S., Di Bucchianico G., Vallicelli A. (eds) Advances in Human Aspects of Transportation. Advances in Intelligent Systems and Computing, vol 484. Springer, Cham. https://doi.org/10.1007/978-3-31941682-3_47

90. Escandon Barbosa D et al (2021) Adoption of new technologies in developing countries: the case of autonomous car between Vietnam and Colombia. Technology in Society. 66:101674

91. Thomas A, Trost J (2017) A study on implementing autonomous intra city public transport system in developing countries - India. Procedia Comp Sci. 375-382:1877-509. https://doi.org/ 10.1016/j.procs.2017.09.093

92. Johnson C (2017) Readiness of the road network for connected and autonomous vehicle. London: RAC Foundation

93. Kuutti S, Fallah S, Katsaros K, Dianati M, Mccullough F, Mouzakitis A (2018) A survey of the state of the art localisation techniques and their potentials for autonomous vehicle applications. IEEE Int Things J. https://doi.org/10.1109/JIOT.2018.2812300

94. Huggins R et al. (2017) Assessment of Key Road Operator Actions to Support Automated Vehicles. Austroads. Research Report AP-R543-17

95. Sage A (2016) Where's the Lane? Self-driving Cars Confused by shabby US roadways. Available: https://www.reuters.com/artic le/us-autos-autonomous-infrastructure-insig/wheres-the-lane-s e lf-drivingcars-confused-by-shabby-u-s-roadways-idUSKCNOWX131

96. EuroRAP (2013) Roads that Cars Can Read: A quality standard for road markings and traffic signs on major rural roads. Available : www.eurorap.org/wp-content/uploads/2015/03/roads_that_ cars_can_read_2_spread1.pdf

97. Huq A, Kamol Debnath D, Nadia M, Nazmus S (2021) The evidence of critical issues in transportation infrastructures of Bangladesh to introduce connected and autonomous. Vehicles. https:// doi.org/10.11159/iccste21.164

98. Infrastructure Partnerships Australia (2017) Automated vehicles: do we know which road to take. Internetine prieiga

99. Schoettle B, Sivak M (2015) Motorists' preferences for different levels of vehicle automation. University of Michigan, Ann Arbor, Transportation Research Institute

100. Liu Y, Tight M, Sun Q, Kang R (2019) A systematic review: road infrastructure requirement for connected and autonomous vehicles (CAVs). J Phys: Conf Ser 1187:042073. https://doi.org/ 10.1088/1742-6596/1187/4/042073

101. Lyon B, Hudson N, Twycross M, Finn D, Porter S, Maklary Z, Waller T (2017) Automated vehicles: Do we know which road to take? Infrastructure Partnerships Australia

102. UK Autodrive (2018) Paving the Way: Building the Road Infrastructure of the Future for the Connected and Autonomous Vehicles. Available: http://www.ukautodrive.com/downloads/

103. SAE (2018) Taxonomy and Definitions for Terms Related to Driving Automation Systems for On-Road Motor Vehicles. J3016_201806

104. Kalaiselvi R, Ramachandraiah A (2016) Honking noise corrections for traffic noise prediction models in heterogeneous traffic conditions like India. Appl Acoust. 25-38:0003-682X. https:// doi.org/10.1016/j.apacoust.2016.04.003

105. Narayanan S, Chaniotakis M, Antoniou C (2020) Shared autonomous vehicle services: a comprehensive review. Transport Res Part C Emerg Technol. 111:255-293. https://doi.org/10.1016/j. trc.2019.12.008

106. Kopelias P, Demiridi E, Vogiatzis K, Skabardonis A, Zafiropoulou V (2019) Connected \& autonomous vehicles - environmental impacts - a review. Sci Total Environ 712:135237. https://doi. org/10.1016/j.scitotenv.2019.135237
107. Spence J, Kim Y, Lamboglia C, Lindeman C, Mangan A, McCurdy A, Stearns J, Wohlers B, Sivak A, Clark M (2020) Potential impact of autonomous vehicles on movement behavior: a scoping review. Am J Prev Med. https://doi.org/10.1016/j. amepre.2020.01.010

108. Sohrabi S, Khreis H, Lord D (2020) Impacts of autonomous vehicles on public health: a conceptual model and policy recommendations. Sustain Cities Soc 63:102457. https://doi.org/10.1016/j. scs.2020.102457

109. Hao M, Yamamoto T (2018) Shared autonomous vehicles: a review considering car sharing and autonomous vehicles. Asian Transport Stud. 5(1):47-63

110. Gandia RM, Antonialli F, Cavazza BH, Neto AM, Lima DA, Sugano JY, Nicolai I, Zambalde AL (2019) Autonomous vehicles: scientometric and bibliometric review. Transp Rev 39(1):9-28. https://doi.org/10.1080/01441647.2018.1518937

111. Peng J, Hanbin H, Zhan F, Chen Y, Shi Y (2020) Agent-based simulation of autonomous vehicles a systematic literature review. IEEE Access. https://doi.org/10.1109/ACCESS.2020.2990295

112. Faisal AM, Yigitcanlar T, Kamruzzaman M, Currie G (2019) Understanding autonomous vehicles: a systematic literature review on capability, impact, planning and policy. J Transport Land Use. https://doi.org/10.5198/jtlu.2019.1405

113. Sun Y, Olaru D, Smith B, Greaves S, Collins A (2017) Road to autonomous vehicles in Australia: an exploratory literature review. Road and Transport Res 26:34-47

114. Piao J, McDonald M, Hounsell N, Graindorge M, Graindorge T, Malhene N (2016) Public views towards implementation of automated vehicles in urban areas. Transport Res Procedia 14:2168-2177

115. Wintersberger P. et al. (2016). Automated Driving System, Male, or Female Driver. Proceedings of the 8th International Conference on Automotive User Interfaces and Interactive Vehicular Applications - Automotive'UI. 16 51-58

116. Schoettle, B; Sivak, M. A (2014) Survey of Public Opinion about Autonomous and Self-Driving Vehicles in the U.S., the U.K., and Australia

117. Cunningham, M. et al. (2018) A survey of public opinion on automated vehicles in Australia and New Zealand. In: 28th ARRB International Conference, Brisbane, Queensland, Australia

118. Compass Transportation and Technology prepared for: Securing America's Future Energy (SAFE) (2018) The Economic and Social Value of Autonomous Vehicles: Implications from Past Network-Scale Investments

119. Clark BY; Larco N, Mann RF (2017) The Impacts of Autonomous Vehicles and E-Commerce on Local Government Budgeting and Finance. 2017

120. Abraham $\mathrm{H}$ et al. (2017) Autonomous Vehicles and Alternatives to Driving: Trust, Preferences, and Effects of Age. Transportation Research Board 96th Annual Meeting

121. Richardson E Davies P (2018) The Changing Public's Perception of Self-Driving Cars

122. University of Illinois College of Engineering (2019) "Platform for testing of autonomous vehicle safety." ScienceDaily. ScienceDaily, 25 October 2019. www.sciencedaily.com/releases/2019/ 10/191025170813.htm

123. Sivak, and Schoettle, Road safety with self-driving vehicles: general limitations and road sharing with conventional vehicles (University of Michigan, Ann Arbor, Transportation Research Institute, 2015-01)

124. Walker (2020) "Are self-driving cars safe for our cities?" https://www.curbed.com/2016/9/21/12991696/drive rless-cars-safety-pros-cons

125. Papadoulis A et al (2019) Evaluating the safety impact of connected and autonomous vehicles on motorways. Accid Analy \& Prevent. 124:12-22 
126. Ye L, Yamamoto T (2019) Evaluating the impact of connected and autonomous vehicles on traffic safety, Physica A: Statistical Mechanics and its Applications. 526 121009. https://doi.org/10. 1016/j.physa.2019.04.245

127. Stewart (2019) "Self-driving cars have to be safer than regular cars. The question is how much" vox, record https:// www. vox.com/recode/2019/5/17/18564501/self-drivi ng-car-morals-safety-tesla-waymo

128. Tibken (2018) "Waymo CEO: Autonomous cars won't ever be able to drive in all conditions" cnet https://www.cnet.com/news/ alphabet-google-waymo-ceo-john-krafcik-autonomous-carswont-ever-be-able-to-drive-in-all-conditions/

129. Lori (2019) "Are Self-Driving Cars Safe?" Verizon connect https://www.verizonconnect.com/resources/article/are-self-drivi ng-cars-safe/

130. Nishimoto, A. (2016). All New Tesla Models Will Feature Level 5-Capable Autopilot Hardware. Automobile news. https://www. motortrend.com/news/new-tesla-models-will-feature-level-5capable-autopilot-hardware/ 